\title{
PAPERS FROM ACTUARIAL JOURNALS WORLDWIDE
}

Single copies of all the papers listed here can be obtained, subject to charge and copyright regulations, from the actuarial profession's libraries. Issues may be borrowed by members. Tel: 01312401311 or 0207632 2114; email: libraries@actuaries.org.uk

\section{ASTIN Bulletin}

$42(1), 2012$

\begin{abstract}
ARBENZ, P.; CANESTRABO, D. Estimating copulas for insurance from scarce observations, expert opinion and prior information: a Bayesian approach. 271-290. A prudent assessment of dependence is crucial in many stochastic models for insurance risks. Copulas have become popular to model such dependencies. However, estimation procedures for copulas often lead to large parameter uncertainty when observations are scarce. In this paper, the authors propose a Bayesian method which combines prior information (e.g. from regulators), observations and expert opinion in order to estimate copula parameters and determine the estimation uncertainty. The combination of different sources of information can significantly reduce the parameter uncertainty compared to the use of only one source. The model can also account for uncertainty in the marginal distributions. Furthermore, the authors describe the methodology for obtaining expert opinion and explain involved psychological effects and popular fallacies. They exemplify the approach in a case study.
\end{abstract}

BÜHLMANN, H.; CZAPIEWSKI, C.; HAVNING, M.; JOHANSEN, S. Obituary: Paul Johansen, the first Chairman of ASTIN has died. 385-387. Obituary.

CHANG, C. W.; CHANG, J. S. K.; GUAN LIM, K. Global warming, extreme weather events, and forecasting tropical cyclones. 77-101. Global warming has more than doubled the likelihood of extreme weather events, e.g. the 2003 European heat wave, the growing intensity of rain and snow in the Northern Hemisphere, and the increasing risk of flooding in the United Kingdom. It has also induced an increasing number of deadly tropical cyclones with a continuing trend. Many individual meteorological dynamic simulations and statistical models are available for forecasting hurricanes but they neither forecast well hurricane intensity nor produce clear-cut consensus. The authors develop a novel hurricane forecasting model by straddling two seemingly unrelated disciplines - physical science and finance - based on the well known price discovery function of trading in financial markets. Traders of hurricane derivative contracts employ all available forecasting models, public or proprietary, to forecast hurricanes in order to make their pricing and trading decisions. By using transactional price changes of these contracts that continuously clear the market supply and demand as the predictor, and with calibration to extract the embedded hurricane information by developing hurricane futures and futures option pricing models, one can gain a forward-looking market-consensus forecast out of all of the individual forecasting models employed. Our model can forecast when a hurricane will make landfall, how destructive it will be, and how this destructive power will evolve from inception to landing. 
While the NHC (National Hurricane Center) blends 50 plus individual forecasting results for its consensus model forecasts using a subjective approach, our aggregate is market-based. Believing their proprietary forecasts are sufficiently different from our market-based forecasts, traders could also examine the discrepancy for a potential trading opportunity using hurricane derivatives. The authors also provide a real case analysis of Hurricane Irene in 2011 using our methodology.

DAHMS, R. Linear stochastic reserving methods. 1-34. In this article the authors want to motivate and analyse a wide family of reserving models, called linear stochastic reserving methods (LSRMs). The main idea behind them is the assumption that the (conditionally) expected changes of claim properties during a development period are proportional to exposures which depend linearly on the past. This means the discussion about the choice of reserving methods can be based on heuristic reasons about exposures driving the claims development, which in our opinion is much better than a pure philosophic approach. Moreover, the assumptions of LSRMs do not include the independence of accident periods. We will see that many common reserving methods, like the Chain-Ladder-Method, the Bornhuetter-Ferguson-Method and the Complementary-LossRatio-Method, can be interpreted in this way. But using the LSRM framework you can do more. For instance you can couple different triangles via exposures. This leads to reserving methods which look at a whole bundle of triangles at once and use the information of all triangles in order to estimate the future development of each of them. We will present unbiased estimators for the expected ultimate and estimators for the mean squared error of prediction, which may become an integral part of IFRS 4. Moreover, we will look at the one period solvency reserving risk, which already is an important part of Solvency II, and present a corresponding estimator. Finally we will present two examples that illustrate some features of LSRMs.

DELONG, L. No-good-deal, local mean-variance and ambiguity risk pricing and hedging for an insurance payment process. 203-232. We study pricing and hedging for an insurance payment process. We investigate a Black-Scholes financial model with stochastic coefficients and a payment process with death, survival and annuity claims driven by a point process with a stochastic intensity. The dependence of the claims and the intensity on the financial market and on an additional background noise (correlated index, longevity risk) is allowed. We establish a general modelling framework for no-good-deal, local mean-variance and ambiguity risk pricing and hedging. We show that these three valuation approaches are equivalent under appropriate formulations. We characterize the price and the hedging strategy as a solution to a backward stochastic differential equation. The results could be applied to pricing and hedging of variable annuities, surrender options under an irrational lapse behaviour and mortality derivatives.

DESMEDT, S.; SNOUSSI, M.; CHENUT, X.; WALHIN, J. F. Experience and exposure rating for property per risk excess of loss reinsurance revisited. 233-270. Experience and exposure rating are traditionally considered to be independent but complementary methods for pricing property per risk excess of loss reinsurance. Strengths and limitations of these techniques are well-known. In practice, both methods often lead to quite different prices. In this paper we show that limitations of traditional experience rating can be overcome by taking into account historical profile information by means of exposure curves. For pricing unused or rarely used capacity, we propose to use exposure rating, calibrated on the experience rate of a working layer. We compare the method presented with more traditional methods based on the information which is generally available to the reinsurer.

HERAS, A.; BALBÁS, B.; VILAR, J. L. Conditional tail expectation and premium calculation. 325-342. In this paper we calculate premiums which are based on the minimization of the 
Expected Tail Loss or Conditional Tail Expectation (CTE) of absolute loss functions. The methodology generalizes well known premium calculation procedures and gives sensible results in practical applications. The choice of the absolute loss becomes advisable in this context since its CTE is easy to calculate and to understand in intuitive terms. The methodology also can be applied to the calculation of the VaR and CTE of the loss associated with a given premium.

KALUSZKA, M.; KRZESZOWIEC, M. Mean-Value Principle under Cumulative Prospect Theory. 103-122. In the paper we introduce a generalization of the mean-value principle under Cumulative Prospect Theory. This new method involves some well-known ways of pricing insurance contracts described in the actuarial literature. Properties of this premium principle, such as translation and scale invariance, additivity for independent risks, risk loading and others are studied.

LANDSMAN, Z.; TSANAKAS, A. Parameter uncertainty in exponential family tail estimation. 123-152. Actuaries are often faced with the task of estimating tails of loss distributions from just a few observations. Thus estimates of tail probabilities (reinsurance prices) and percentiles (solvency capital requirements) are typically subject to substantial parameter uncertainty. We study the bias and MSE of estimators of tail probabilities and percentiles, with focus on 1-parameter exponential families. Using asymptotic arguments it is shown that tail estimates are subject to significant positive bias. Moreover, the use of bootstrap predictive distributions, which has been proposed in the actuarial literature as a way of addressing parameter uncertainty, is seen to double the estimation bias. A bias corrected estimator is thus proposed. It is then shown that the MSE of the MLE, the parametric bootstrap and the bias corrected estimators only differ in terms of order $\mathrm{O}\left(n^{-2}\right)$, which provides decision-makers with some flexibility as to which estimator to use. The accuracy of asymptotic methods, even for small samples, is demonstrated exactly for the exponential and related distributions, while other 1-parameter distributions are considered in a simulation study. We argue that the presence of positive bias may be desirable in solvency capital calculations, though not necessarily in pricing problems.

LEE, S. C. K.; LIN, X. S. Modelling dependent risks with multivariate Erlang mixtures. 153-180. In this paper, we introduce a class of multivariate Erlang mixtures and present its desirable properties. We show that a multivariate Erlang mixture could be an ideal multivariate parametric model for insurance modelling, especially when modelling dependence is a concern. When multivariate losses are governed by a multivariate Erlang mixture, many quantities of interest such as joint density and Laplace transform, moments, and Kendall's tau have a closed form. Further, the class is closed under convolutions and mixtures, which enables us to model aggregate losses in a straightforward way. We also introduce a new concept called quasi-comonotonicity that can be useful to derive an upper bound for individual losses in a multivariate stochastic order and upper bounds for stop-loss premiums of the aggregate loss. Finally, an EM algorithm tailored to multivariate Erlang mixtures is presented and numerical experiments are performed to test the efficiency of the algorithm.

LU, Y.; ZENG, L. A nonhomogeneous Poisson hidden Markov model for claim counts. 181-202. We propose a nonhomogeneous Poisson hidden Markov model for a time series of claim counts that accounts for both seasonal variations and random fluctuations in the claims intensity. It assumes that the parameters of the intensity function for the nonhomogeneous Poisson distribution vary according to an (unobserved) underlying Markov chain. This can apply to natural phenomena that evolve in a seasonal environment. For example, hurricanes that are 
subject to random fluctuations (El Niño-La Niña cycles) affect insurance claims. The ExpectationMaximization (EM) algorithm is used to calculate the maximum likelihood estimators for the parameters of this dynamic Poisson hidden Markov model. Statistical applications of this model to Atlantic hurricanes and tropical storms data are discussed.

MARTÍNEZ MIRANDA, M. D.; NIELSEN, J. P.; VERRALL, R. Double chain ladder. 59-76. By adding the information of reported count data to a classical triangle of reserving data, we derive a surprisingly simple method for forecasting IBNR and RBNS claims. A simple relationship between development factors allows to involve and then estimate the reporting and payment delay. Bootstrap methods provide prediction errors and make possible the inference about IBNR and RBNS claims, separately.

NAKANO, Y. On approximating law-invariant comonotonic coherent risk measures. 343-353. The optimal quantization theory is applied for approximating law-invariant comonotonic coherent risk measures. Simple $L^{p}$-norm estimates for the risk measures provide the rate of convergence of that approximation as the number of quantization points goes to infinity.

ROSENLUND, S. Bootstrapping individual claim histories. 291-324. The bootstrap method BICH is given for estimating mean square prediction errors and predictive distributions of non-life claim reserves under weak conditions. The dates of claim occurrence, reporting and finalization and the payment dates and amounts of individual finalized historic claims form a claim set from which samples with replacement are drawn. We assume that all claims are independent and that the historic claims are distributed as the object claims, possibly after inflation adjustment and segmentation on a background variable, whose distribution could have changed over time due to portfolio change. Also we introduce the new reserving function RDC, using all these dates and payments for reserve predictions. We study three reserving functions: chain ladder, the Schnieper (1991) method and RDC. Checks with simulated cases obeying the assumptions of Mack (1999) for chain ladder and Liu and Verrall (2009) for Schnieper's method, respectively, confirm the validity of our method. BICH is used to compare the three reserving functions, of which RDC is found overall best in simulated cases.

SALZMANN, R.; WÜTHRICH, M. V.; MERZ, M. Higher moments of the claims development result in general insurance. 355-384. The claims development result (CDR) is one of the major risk drivers in the profit and loss statement of a general insurance company. Therefore, the CDR has become a central object of interest under new solvency regulation. In current practice, simple methods based on the first two moments of the CDR are implemented to find a proxy for the distribution of the CDR. Such approximations based on the first two moments are rather rough and may fail to appropriately describe the shape of the distribution of the CDR. In this paper we provide an analysis of higher moments of the CDR. Within a Bayes chain ladder framework we consider two different models for which it is possible to derive analytical solutions for the higher moments of the CDR. Based on higher moments we can e.g. calculate the skewness and the excess kurtosis of the distribution of the CDR and obtain refined approximations. Moreover, a case study investigates and answers questions raised in IASB [9].

VERRALL, R.; HÖSSJER, O.; BJÖRKWALL, S. Modelling claims run-off with reversible jump Markov chain Monte Carlo methods. 35-58. In this paper we describe a new approach to modelling the development of claims run-off triangles. This method replaces the usual ad hoc practical process of extrapolating a development pattern to obtain tail factors with an 
objective procedure. An example is given, illustrating the results in a practical context, and the WinBUGS code is supplied.

Reproduced with the permission of ASTIN.

Members of ASTIN and AFIR receive ASTIN Bulletin free of charge. Members of the Institute and Faculty of Actuaries can join ASTIN and AFIR by contacting Georgina Warren (Georgina.Warren@actuaries.org.uk) at the Institute and Faculty of Actuaries.

Libraries, insurers, and individuals who are not members of the Faculty or Institute can subscribe to ASTIN Bulletin by contacting the publisher, Peeters, Journals Department, Bondgenotenlaan 153, B-3000 Leuven, Belgium. E-mail: peeters@peeters-leuven.be

\section{European Actuarial Journal}

1(1) July, 2011

ALBRECHER, H.; GERBER, H. U.; SHIU, E. S. W. The optimal dividend barrier in the GammaOmega model. 43-55. In the traditional actuarial risk model, if the surplus is negative, the company is ruined and has to go out of business. In this paper we distinguish between ruin (negative surplus) and bankruptcy (going out of business), where the probability of bankruptcy is a function of the level of negative surplus. The idea for this notion of bankruptcy comes from the observation that in some industries, companies can continue doing business even though they are technically ruined. Assuming that dividends can only be paid with a certain probability at each point of time, we derive closed-form formulas for the expected discounted dividends until bankruptcy under a barrier strategy. Subsequently, the optimal barrier is determined, and several explicit identities for the optimal value are found. The surplus process of the company is modelled by a Wiener process (Brownian motion).

ASMUSSEN, S.; BIARD, R. Ruin probabilities for a regenerative Poisson gap generated risk process. 3-22. A risk process with constant premium rate $c$ and Poisson arrivals of claims is considered. A threshold $r$ is defined for claim interarrival times, such that if $k$ consecutive interarrival times are larger than $r$, then the next claim has distribution $G$. Otherwise, the claim size distribution is $F$. Asymptotic expressions for the infinite horizon ruin probabilities are given for both light- and the heavy-tailed cases. A basic observation is that the process regenerates at each $G$-claim. Also an approach via Markov additive processes is outlined, and heuristics are given for the distribution of the time to ruin.

CHAUVIGNY, M.; DEVINEAU, L.; LOISEL, S.; MAUME-DESCHAMPS, V. Fast remote but not extreme quantiles with multiple factors: applications to Solvency II and Enterprise Risk Management. 131-157. For operational purposes, in Enterprise Risk Management or in insurance for example, it may be important to estimate remote (but not extreme) quantiles of some function $\mathrm{f}$ of some random vector. The call to $f$ may be time- and resource-consuming so that one aims at reducing as much as possible the number of calls to $f$. In this paper, we propose some ways to address this problem of general interest. We then numerically analyze the performance of the method on insurance and Enterprise Risk Management real-world case studies.

EISELE, K.-T.; ARTZNER, P. Multiperiod insurance supervision: top-down models. 107-130. We describe a top-down procedure for the supervisory accounting of insurance companies with 
special emphasis on market impacts. The technical tools are a multiperiod risk assessment, a market consistent best estimate and an eligible asset. First, to avoid supervisory arbitrage by financial market instruments, the risk assessment is bounded by a market consistent best estimate. Applied to the risk bearing capital, i.e. asset value minus best estimate of obligations, the risk assessment immediately gives the free capital which has to be positive for acceptability. Next, optimal hedging of the obligation process by suitable asset portfolios yields the supervisory provision as the minimal initial value of a portfolio acceptable with respect to the given obligations. The problem to attain this minimal value leads to the definition of an optimal replicating portfolio. A further task of supervision is the determination of the "Fremd"-capital in the supervisory balance sheet. This is formalized by the cost-of-capital method, i.e. a fictitious standardized transfer of the obligations to new investors on the market. The regulated price of such a transfer leads to the technical provision and the risk margin as "Fremd"-capital items. Finally, the additional financial risks within the insurance's real asset portfolio are taken care of by the solvency capital requirement defined as the minimal acceptable "Eigen"-capital for a given business plan. It measures the adequacy or inadequacy of the trading risks incorporated in the portfolio with respect to the obligation risks. An optimal replicating portfolio is characterized by a minimal solvency capital requirement. Solvency II and the Swiss Solvency Test (SST) are defined as bottom-up models. In the forthcoming paper Eisele and Artzner (2011), we shall show how bottom-up and top-down models can be made congruent.

GSCHLÖSSL, S.; SCHOENMAEKERS, P.; DENUIT, M. Risk classification in life insurance: methodology and case study. 23-41. In this paper, we describe how Poisson regression analysis can be efficiently used to perform graduation of mortality rates in presence of exogenous information supporting an efficient underwriting process in life insurance business. After having justified the relevance of a Poisson likelihood for mortality data, we explain how categorical and continuous covariates can be included in the model. A case study based on a German insurance portfolio is proposed to illustrate the usefulness of the approach described in this paper.

HIPP, C. Editorial: European Actuarial Journal. 1-2. The editors welcome readers to this new international scientific journal which is published and edited by a cooperation of 13 actuarial associations of the following 11 countries: Austria, Belgium, France, Germany, Greece, Hungary, Italy, Poland, Portugal, Slovenia, and Switzerland. European Actuarial Journal is the successor of the following six actuarial journals: 1. Belgian Actuarial Bulletin, 2. Blätter der Deutschen Gesellschaft für Versicherungs- und Finanzmathematik, 3. Boletim do Instituto dos Actuários Portugueses, 4. Giornale dell'Istituto Italiano degli Attuari, 5. Mitteilungen der Schwweiserische Aktuarveringung/Bulletin de l'Association Suisse des Actuaires, 6. Mitteilungen der Aktuarveringung Österreichs (Austria).

SCHEER, N.; SCHMIDLI, H. Optimal dividend strategies in a Cramer-Lundberg model with capital injections and administration costs. 57-92. In this paper, we consider a classical risk model with dividend payments and capital injections in the presence of both fixed and proportional administration costs. Negative surplus or ruin is not allowed. We measure the value of a strategy by the discounted value of the dividends minus the costs. It turns out capital injections are only made if the claim process falls below zero. Further, at the time of an injection the company may not only inject the deficit, but inject additional capital $C \geqslant 0$ to prevent future capital injections. We derive the associated Hamilton-Jacobi-Bellman equation and show that the optimal strategy is of band type. By using Gerber-Shiu functions, we derive a method to determine numerically the solution to the integro-differential equation and the unknown value $C$. 
WÜTHRICH, M. V. An academic view on the illiquidity premium and market-consistent valuation in insurance. 93-105. The insurance industry currently discusses to which extent they can integrate an illiquidity premium into their best estimate considerations of insurance liabilities. The present position paper studies this question from an actuarial perspective that is based on market-consistent valuation. We conclude that mathematical theory does not allow for discounting insurance liabilities with an illiquidity spread.

\section{European Actuarial Journal}

\section{1(1) Supplement 1, 2011}

BALESTRERI, A.; KENT, J.; MORGAN, E. Dynamic asset liability management: a method for optimising investment strategy. 29-46. In recent years, many insurers have done significant work on their asset-liability management (ALM). Many life insurers have very sophisticated models of their assets and liabilities, although often the focus of these has not been on operational ALM and about the use of models to improve the investment strategy of the companies, but rather on longer-term projections for MCEV or economic capital. Therefore, it seems timely to discuss what advances can be made in the area of dynamic asset liability management.

CHRISTIANSEN, M. C. Making use of netting effects when composing life insurance contracts. 47-60. In this paper, we discuss netting effects in life insurance policies provided by the natural hedge between payments that are due when sojourning in a state and when leaving a state. We uncover potentials for such netting effects with the help of a sensitivity analysis, and we quantify the effect on solvency reserves with the help of a worst-case analysis. The paper discusses a number of examples where netting effects occur and shows for which ratios between different benefit types the netting effects are strongest.

GROYER, A.; KREIENSIEK, I. Assessing critical illness trends: the facts behind the stats. 61-84. This study assesses the effect of changes observed on population level data for major critical illness conditions on current and future expected claim rates. Main focus is identifying the underlying reasons for changes seen in the past to distinguish between once-off effects and those that can reasonably be expected to continue. Adjustments are made to allow for differences between trends in insured lives and the general population. Developments on the horizon that could affect future claim rates are also considered. As examples of the work done this paper discusses trends for heart attacks and the effect of screening for cancer.

KRYGER, E. M. Fairness versus efficiency of pension schemes. 85-100. The benefits that members of with-profits pension schemes obtain are determined by the scheme design and the controlled funding level at the time of entry. This paper examines efficiency and intergenerational fairness of with-profits pension schemes.

OLIVIERI, A. Stochastic mortality: experience-based modelling and application issues consistent with Solvency 2. 101-125. This paper is motivated by the need to have appropriate tools for the valuation of mortality/longevity risks when carrying out an internal assessment of the insurance business, such as a portfolio valuation or a solvency investigation based on internal models. The case of life annuities is in particular addressed, due to the importance of mortality/longevity on the cost of living benefits for the elderly. Our aim is to describe a stochastic mortality model 
calibrated on the best-estimate life table available to the insurer and to the mortality experienced in the insurer's portfolio. As we address life annuities, uncertainty of future mortality improvements, i.e. the aggregate mortality/longevity risk, needs in particular to be accounted for. Following Olivieri and Pitacco (ASTIN Bulletin 39(2):541-563, 2009), we extend some classical results about the modelling of the number of deaths joint to the modelling of parameter uncertainty. We explore the features of two alternative approaches: a Beta-Binomial and a Poisson-Gamma setting; we then focus on the latter only. Thanks to a Bayesian inferential procedure, the parameters, initially assigned referring to the best-estimate life table, are updated according to the mortality experienced in the portfolio. Extending a traditional tool-kit, the framework we define is in particular suitable for practical work. Due to calibration, clearly the scope of the model is within internal assessments. To provide an example of application of the model, we perform a capital assessment. Solvency rules which could be adopted as an alternative to a standard, regulatory requirement are tested. The Solvency 2 requirement for longevity risk is referred to for the design of an internal rule which could get validation for replacing the standard one.

TORRI, T. Building blocks for a mortality index: an international context. 127-141. Reforms of European public pension systems coupled with reduced financial returns, lately increased the importance of longevity risk. The need to hedge a systematic risk, spurred the development of securitization. Financial engineers are very active in designing new mortality-linked securities and underlying mortality indexes. I present here three alternative models from the time series analysis (ARIMA (autoregressive integrated moving average), VAR (vector autoregressive) and VEC (vector error correction)), used to compute future values of life expectancy. A comparison of their forecast accuracy returns the VAR as the best performer. This is telling us that not necessarily the more adequate VEC model is also the more accurate.

\section{European Actuarial Journal}

\section{1(1) Supplement 2, 2011}

ARO, H.; PENNANEN, T. A user-friendly approach to stochastic mortality modelling. 151-167. This paper proposes a general approach to stochastic mortality modelling. The logit transforms of annual survival probabilities are modelled by a linear combination of user-specified basis function of age. The model is easy to calibrate using the maximum likelihood method. The flexible construction and tangible interpretation of the underlying risk factors allows for an easy incorporation of population-specific characteristics and user views into the model. We fit two versions of the model into Finnish adult (18-100 years) population and mortality data, and present simulations for the future development of life spans.

BAIER, A. An integrated cost of risk model and its application to company valuation. 169-184. This paper proposes an integrated approach of measuring risk and the associated cost. The model is developed from the simple practical example of a bond spread and then generalized. This leads to a class which encompasses spectral risk measures and hence includes the popular measures Value at Risk and Tail Value at Risk and under certain conditions is coherent. The defining equations lead to a "natural" decomposition by sub portfolio under practical conditions. In an application section market data is used to parametrize the measure and evaluate the capital cost of an example company. 
BERTSCHI, L.; ROUECHE, J.; MUNARETTO, N. Solvency requirements for Swiss pension funds and how to ensure the guarantee of benefit payments at any time. 185-197. We develop an approach for practitioners for setting up the target value of investment fluctuation reserves for autonomous Swiss pension funds and determine a desirable level for them to better ensure benefits payments during times of volatile financial markets. The Swiss pension legislation does not stipulate any methodology and requirements for setting up such reserves. We give an overview of methods used and suggest some improvements based on our experience as many pension funds are underfunded after 2008. A suggested approach will help trustees to better comply with funding and solvency requirements for Swiss pension funds.

CHETOUANE, M. How can defined contribution pension plans benefit from momentum and mean reversion? 199-231. In this paper, we assess whether the stock market downturn can be an opportunity for Defined Contribution pension plan members to reinforce their risky assets exposure? In line with the framework developed by Kojein et al. (Management Sciences 55(7), 1199-1213, 2009), we consider a DC plan investor, during the accumulation phase, whose aim is to maximize his terminal wealth. Within a continuous portfolio choice model, in which stock returns exhibit both momentum and mean reversion, DC plan members are allowed to invest their pension wealth into stocks as well as cash and bond assets. We derived the optimal portfolio candidate and we show how a DC plan investor can benefit from market opportunities by taking advantage of the momentum and mean reversion stock return properties. We find that long term investors such as DC plan members would benefit from a temporary increase of the share of risky assets in their portfolio in preparation of their retirement.

DAHL, M.; GLAR, S.; MØLLER, T. Mixed dynamic and static risk-minimization with an application to survivor swaps. 233-260. In the traditional setup, the financial market consists of liquid and dynamically traded financial assets. Here, we extend this setup to include an illiquid asset, which may be traded at fixed, discrete times only. Within this setting of mixed dynamic and static hedging, we adopt the criterion of risk-minimization and minimize the so-called risk process at the fixed trading times for the illiquid asset. The optimal mixed dynamic and static risk-minimizing strategies are compared with the optimal dynamic strategies, and certain correction terms that arise, when trading is restricted to discrete time for the illiquid asset, are identified. We apply the technique for a life insurance company whose liabilities are described by a general insurance payment process. Here, the traditional financial market contains a savings account and a zero coupon bond, which may be traded continuously, and an illiquid mortality derivative, traded at fixed times. We provide numerical illustrations with survivor swaps and compare the minimum obtainable risk with the risk for the optimal dynamic strategies.

DOTTERWEICH, A.; KÖSTNER, S. Optimisation of limit systems for investment risks in accordance with Solvency II. 283-302. In order to satisfy the requirements of Solvency II (e.g. Framework directive on the EU Solvency II Project on Safety Measures and its implementation according to $\S 64$ a German Insurance Law)-insurance companies should implement an overall risk limit system. The starting point for developing this system is the entity's risk strategy and risk bearing capital approach based on economic principles. For life insurance companies, the dominant risk category is investment risk. Therefore, the limit system should focus on such risks. In practice there are multiple interactions between the core life insurance business and the asset side. Because of these interactions, a limit system for investment risks cannot be separated from life business risks. There is a particular need to integrate the entity's asset liability management approach into the risk limit system. The regulatory requirements call for consistent integration of 
a top-down view with a bottom-up risk management perspective in the investment department. In creating an adequate system, the first step is to categorise the individual types of risk and the corresponding risk management approaches. It is most important to get clear definitions of the bottom-up and the top-down views in the context of life insurance investment risks, and to integrate these into the entity's overall solvency control regime. The current financial crisis has revealed problems of valuation and an enormous and unprecedented increase in volatility in the capital markets. It is clear that an ongoing and effective analysis of these market developments and their impact on asset allocation and portfolio optimisation is necessary. The crisis also implies the need to think in detail about how to manage model risk implications. In this paper we propose an integrated view of these issues as the basis for optimal design of the company's risk limit system.

GILLI, M.; SCHUMANN, E. Risk-reward optimisation for long-run investors: an empirical analysis. 303-327. A common approach in portfolio selection is to characterise a portfolio of assets by a desired property, the reward, and something undesirable, the risk. These properties are often identified with mean and variance of returns, respectively, even though, given the nonGaussian nature of financial time series, alternative specifications like partial and conditional moments, quantiles, and draw-downs seem theoretically more appropriate. We analyse the empirical performance of portfolios selected by optimising risk-reward ratios constructed from such alternative functions. We find that in many cases these portfolios outperform our benchmark (minimum-variance), in particular when long-run returns are concerned. We also find, however, that all the strategies tested (including minimum-variance) are sensitive to relatively small changes in the data. The main theme throughout our analysis is that minimising risk, as opposed to maximising reward, leads to good out-of-sample performance. Adding a reward-function to the selection criterion usually improves a given strategy only marginally.

HILLI, P.; KOIVU, M.; PENNANEN, T. Cash-flow based valuation of pension liabilities. 329-343. This paper presents a computational framework for cash-flow based valuation of insurance liabilities in incomplete markets. It accounts for the risks associated with both insurance claims and investment returns until maturity in accordance with modern principles of asset-liability management. The valuation framework is market consistent in the sense that it takes into account the investment opportunities available to the insurer at the time of valuation. The framework is easily adapted to different lines of insurance and it can effectively employ advanced tools for strategic portfolio management. As an application, we value the insurance portfolio of the Finnish private sector occupational pension system where the liabilities extend over 82 years.

HILLI, P.; KOIVU, M.; PENNANEN, T. Optimal construction of a fund of funds. 345-359. The authors study the problem of diversifying a given initial capital over a finite number of investment funds that follow different trading strategies. The investment funds operate in a market where a finite number of underlying assets may be traded over finite discrete time. The authors present a numerical procedure for finding a diversification that is optimal in the sense of a given convex risk measure. The procedure is illustrated on an asset-liability management problem where the liabilities correspond to a pension insurance portfolio.

JIE DING, J.; SHERRIS, M. Comparison of market models for measuring and hedging synthetic CDO tranche spread risks. 261-281. The recent credit crisis has focused attention on the models used for pricing and assessing risk of structured credit transactions including synthetic CDOs [collateralised debt obligations]. The market standard one factor Gaussian copula model has been 
criticized for its unrealistic constant correlation assumption. In this paper, a range of market models that allow a positive relationship between default correlation and default probability, including the correlation mapping methods and the implied copula models, are compared with the Gaussian copula model, based on their relative performance in hedging credit spread risk and pricing bespoke CDOs. The models assessed are calibrated to the traded CDO tranche spreads prior to the credit crisis and then compared based on the mean absolute pricing errors over a time period including the credit crisis. The results of the analysis highlight a number of issues including the accuracy of "mark-to-model" valuations of bespoke CDOs, the value of including past information in pricing and hedging, and the relative performance of the base correlation Gaussian copula model compared to the other market models in this study.

KORN, R.; SIU, T. K.; ZHANG, A. Asset allocation for a DC pension fund under regime switching environment. 361-377. The authors consider the portfolio selection problem of a member of a defined contribution pension plan in a hidden Markov-modulated economy modulated by a continuous-time, finite-state, hidden Markov chain whose states represent different hidden states of the underlying economy. The evolution of the chain over time is not observable by the member. We consider the situation that the member aims to maximize the expected utility from terminal wealth. This utility maximization problem of the member is a stochastic optimal control problem with partial observations. The authors adopt the innovations approach in filtering theory to transform the problem into one with complete observations. They develop a robust filter for the hidden state of the economy and present a robust-filter-based EM algorithm for estimating the unknown parameters.

KRUSE, S. On the pricing of inflation-indexed caps. 379-393. The authors consider the problem of pricing inflation-linked caplets in a Black-Scholes-type framework as well as in the presence of stochastic volatility. By using results on the pricing of forward starting options in Heston's Model on stochastic volatility, we derive closed-form solutions for inflation caps which aim to receive smile-consistent option prices. Additionally we price options on the inflation development over a longer time horizon. In this paper we develop a new and more suitable formula for pricing inflation-linked options under the assumption of stochastic volatility. The formula in the presence of stochastic volatility allows to cover the smile effects observed in our Black-Scholes type environment, in which the exposure of year-on-year inflation caps to inflation volatility changes is ignored. The chosen diffusion processes reflect the macro-economic concept of Fisher making a connection between interest rates on the market and the expected inflation rate.

MACMINN, R.; WEBER, F. Select birth cohorts. 395-403. Worldwide demographic changes and their implications for governments, corporations, and individuals have been in the focus of public interest for quite some time due to the fiscal risk related to adequate retirement benefits. Through a more detailed analysis of mortality data an additional type of risk can be identified: differences in mortality improvements by birth year, also known as "cohort effects." Previous contributions have, however, not formalized a suitable measure to further investigate mortality improvements but rather relied on graphical representations without particular focus on individual cohorts but groups of the overall population. No criterion to identify single birth year cohorts as select has been established. A simple criterion for identifying select cohorts is proposed and used here to analyze what country mortality data reveals about the mortality and longevity experience of cohorts. Select cohorts are rare but can be quite different from surrounding cohorts and so may generate financial risks that need to be hedged naturally or artificially with new ART instruments. 
NOBUHIRO, S. Economic values of contribution cashflows for a sponsoring employer of a DB pension plan and measures to bring the economic costs under control within an affordable range. 411-431. In many countries defined-benefit pension plans experienced sudden and significant funding gaps caused by the asset price depreciation and the interest rate decline originated from the global financial crisis erupted in August 2007. This paper explores several measures to bring under control the economic costs of contributions from the aspects of benefit designs, funding standards, and investment strategies. On funding standards, this paper proposes payout-year differentiation of funding standards, under which assets and contributions are divided by payout year and loaded, respectively, on 'sequentially chained containers.' This payout-year specific (PYS) funding standard then specifies a sequence of minimum admissible funded ratios (MAFRs) each of which is assigned to the corresponding container. Each MAFR will be a function of the period from the measurement date to the payout year. The MAFRs will be derived assuming a hypothetical investment strategy of switching the speculative portfolio to a complete liabilityhedging portfolio immediately when the amount of assets surpasses the value of corresponding liabilities. This PYS funding standard allows taking into account the expected excess returns on risky assets to some extent in the discount rates and thus enables us to reduce the volatility of contributions.

PRESSACCO, F.; SERAFINI, P.; ZIANI, L. Mean-variance efficient strategies in proportional reinsurance under group correlation in a gaussian framework. 433-454. The paper concerns optimal mean-variance proportional reinsurance under group correlation. In order to solve the corresponding constrained quadratic optimization problem, we make large recourse both to the smart friendly technique originally proposed by B. de Finetti in his pioneering paper (Giornale Istituto Italiano Attuari 9:1-88, 1940) and to the well known Karush-Kuhn-Tucker conditions for constrained optimization. We offer closed form results and insightful considerations about the problem. In detail, we give closed form formulae to express the efficient mean-variance retention set both in the retention space and in the mean-variance one.

European Actuarial Journal

1(2) November, 2011

AMBRUS, M.; CRUGNOLA-HUMBERT, J.; SCHMID, M. Interest rate risk: dimension reduction in the Swiss Solvency Test. 159-172. Many risk models suffer from the incorporation of too many risk dimensions, which at best only increase computational costs. However, in many cases such models suffer in addition from a poor predictive power, as either the numerous underlying parameters are not understood fully and in order to remain computable the models may be oversimplistic and therefore neglect the more subtle interactions between the main risk drivers. In this paper, we analyze the interest rate risk module of the Swiss Solvency Test Standard Model, where interest rate risk is modelled with 13 risk-factors per currency. We apply the principal component analysis to reduce the dimension of this module. The economic interpretation of the remaining risk-factors becomes obvious, improving the understanding of the model. Further, we suggest to calculate the risk-factor sensitivities at the quantile corresponding to the expected shortfall of the corresponding normally distributed risk-factor. This way the inherent non-linearities are sufficiently allowed for and a complex second order Delta-Gamma approximation could be omitted. A sample calculation based on the SST 2011 for Basler Leben AG is provided to illustrate the validity of our approach with a real world case study. 
BREUER, L. Threshold dividend strategies for a Markov-additive risk model. 237-258. We consider the following risk reserve model. The premium income is a level dependent Markov-modulated Brownian motion. Claim sizes are iid with a phase-type distribution. The claim arrival process is a Markov-modulated Poisson process. For this model the payment of dividends under a threshold dividend strategy and the time until ruin will be analysed.

DEBÓN, A.; MONTES, F.; MARTÍNEZ-RUIZ, F. Statistical methods to compare mortality for a group with non-divergent populations: an application to Spanish regions. 291-308. This paper develops a model to compare geographical differences in the mortality of related regions, taking into account the interdependence between them. Additionally, the model allows us to provide an adequate solution for studying the mortality of a group pertaining to a larger population. It should therefore be possible to improve the mortality analysis for the regions in a country by taking into account the patterns within that country. Using official data from the Spanish National Institute of Statistics (Instituto Nacional de Estadística, INE), we applied a modification of the Lee-Carter model to Spanish regions. The results of this model were then compared with other similar models such as the logit Brass, Li and Lee and Russolillo-Giordano-Haberman. One interesting feature of our model is its simplicity, as the comparison of mortality patterns is accomplished by means of a simple index.

DEVOLDER, P. Revised version of: Solvency requirement for a long-term guarantee: risk measures Versus probability of ruin. 199-214. Solvency requirements are based on the idea that risk can be accepted if enough capital is present. The determination of this minimum level of capital depends on how we consider and measure the underlying risk. Apart from the kind of risk measure used, an important factor is how time is integrated in the process. This topic is particularly important for long-term liabilities such as life insurance or pension benefits. In this paper we study the market risk of a life insurer offering a fixed guaranteed rate on a certain time horizon and investing the premium in a risky fund. We develop and compare various risk measurements based either on a single point analysis or on a continuous-time test. Dynamic risk measures are also considered.

HÜRLIMANN, W. Insurance risk capital for the Sparre Andersen model with geometric Lévy stochastic returns. 215-235. Some multi-period insurance risk economic capital models that include the effects of heavy-tail claims and random returns are considered. They are based on the Sparre Andersen risk model with geometric Lévy stochastic returns. The random accumulated surplus over an arbitrary finite time horizon is decomposed into insurance risk, market risk and future profit components. A protection against the solvency risk of the policyholders is obtained by applying the $\mathrm{VaR}(\mathrm{CVaR})$ measure to the insurance risk component and defines a multi-period insurance risk $\mathrm{VaR}(\mathrm{CVaR})$ economic capital. A classical asymptotic result by Resnick and Willekens [Ref. 28: Resnick SI, Willekens E (1991) Moving averages with random coefficients and random coefficient autoregressive models. Comm. Statist. Stochastic Models 7(4):511-525] on the tail probability of moving averages with random coefficients is applied to the accumulated aggregate claims random variable for claim size distributions with regularly varying tail to derive asymptotic formulas for these multi-period insurance risk economic capitals. Numerical examples with a Pareto claim size distribution reveal interesting features and differences between these two solvency rules. Since the preceding results exclude the log-normal and the heavy-tailed Weibull claim size distributions, we consider also an extension to sub-exponential claim sizes for the compound Poisson model with constant force of interest, which is based on Hao and Tang [Ref. 12: Hao X, Tang Q (2008) A uniform asymptotic estimate for discounted aggregate claims 
with subexponential tails, Insurance: Mathematics and Economics 43(1):116-120]. The obtained results are compared with the standard Solvency II specification of the non-life insurance risk.

KOCHANSKI, M.; KARNASKI, B. Solvency capital requirement for bybrid products. 173-198. In this paper, we propose a partial internal model to determine the solvency capital requirement (SCR) for static and dynamic hybrid products. We present qualitative and quantitative results from several simulation studies for new business portfolios as well as for existing portfolios based on actual and fictitious historical financial market data. Our findings show that hybrid products are mainly exposed to interest rate, equity and lapse risks. Furthermore, we show that the SCR for dynamic hybrid products strongly depends on past financial market fluctuations.

LOVÁSZ, E. Analysis of Finnish and Swedish mortality data with stochastic mortality models. 259-289. I have compared quantitatively nine stochastic models explaining the improvements in male mortality rates over ages 20-99 in Finland and Sweden. The study was divided in two main parts. In the first part I analysed the fit to historical data starting with the Bayes information criterion and the comparison of nested models. Subsequently, residual series that are predicted to be iid standard normal were assessed by different tests. In the second part I looked at the forecast of the nine stochastic mortality models and the plausibility of the forecasts. An ex-post evaluation of the forecast completed the study. For this I examined the consistency of the forecasts for a fixed future year and the accuracy of 20-years-forecasts against the realised mortality rates. For the considered dataset, there were some notable differences amongst the models, but none of the models performed well in all tests and no model clearly dominated the others. For insurancerelated applications the model of Plat (Insurance: Mathematics and Economics 45(3):393-104, 2009) would be an appropriate choice.

\section{European Actuarial Journal}

2(1) July, 2012

CONSTANTINESCU, C.; MAUME-DESCHAMPS, V.; NORBERG, R. Risk processes with dependence and premium adjusted to solvency targets. 1-20. This paper considers risk processes with various forms of dependence between waiting times and claim amounts. The standing assumption is that the increments of the claims process possess exponential moments so that variations of the Lundberg upper bound for the probability of ruin are in reach. The traditional point of view in ruin theory is reversed: rather than studying the probability of ruin as a function of the initial reserve under fixed premium, the problem is to adjust the premium dynamically so as to obtain a given ruin probability (solvency requirement) for a fixed initial reserve (the financial capacity of the insurer). This programme is carried through in various models for the claims process, ranging from Cox processes with iid claim amounts, to conditional renewal (Sparre Andersen) processes.

GAILLE, S. Forecasting mortality: when academia meets practice. 49-76. Techniques used in practice often differ from tools developed in academia. The lack of communication that may exist between academia and practice can then have important consequences for many insurance companies or pension funds. This issue is illustrated with what is currently happening in Switzerland. Swiss pension funds use mortality tables that are regularly updated with new observations. A new version of these tables has been recently published and includes a procedure 
to forecast mortality until 2150. The method applied for these projections is very different from the several forecasting models that have been developed in academia over the last decades. In this paper, we compare mortality forecasts used by practitioners in Switzerland and the forecasts resulting from two simple approaches well-known in academia, the Lee-Carter model and the Heligman-Pollard function. These two approaches have the advantage of simplicity and thus, all insurance companies and pension funds may implement them without any difficulties. The analysis demonstrates that both academic methods forecast a more important decrease in mortality than the approach applied by pension funds, especially in the long-run and for females. Impacts on pension liabilities are then evaluated, enlightening the future challenges many institutions will face. Finally, a few points which insurance companies or pension funds need to be cautious with, when using mortality forecasts, are summarized.

GRAF, S.; KLING, A.; RUß, J. Financial planning and risk-return profiles. 77-104. The importance of funded private or occupational old age provision will increase due to demographic changes and the resulting challenges for government-run pay-as-you-go systems. Clients and advisors therefore need reliable methodologies to match offered products and clients' needs and risk appetite. In this paper, we show that the information provided by existing approaches such as sample illustrations and historical back-testing that are often used for comparing and explaining products is often insufficient or even misleading. We introduce an alternative methodology based on risk-return profiles, i.e. the (forward-looking) probability distribution of benefits. In a model with stochastic interest rates and equity returns including stochastic equity volatility, we derive risk-return profiles for various types of existing unit-linked/equity-linked products with and without embedded guarantees. In contrast to previous work, we particularly take into account charges, effects resulting from regular premium payments and typical practical restrictions like borrowing constraints, hence providing applicable models adding insights to current political discussions on transparency regulations in several countries. We highlight the differences between actual product characteristics and the impression generated by existing approaches and explain the resulting misleading incentives for product developers and financial advisors.

KORN, R.; MENKENS, O.; STEFFENSEN, M. Worst-case-optimal dynamic reinsurance for large claims. 21-48. We control the surplus process of a non-life insurance company by dynamic proportional reinsurance. The objective is to maximize expected (utility of the) surplus under the worst-case claim development. In the large claim case with a worst-case upper limit on claim numbers and claim sizes, we find the optimal reinsurance strategy in a differential game setting where the insurance company plays against mother nature. We analyze the resulting strategy and illustrate its characteristics numerically. A crucial feature of our result is that the optimal strategy is robust to claim number and size modelling and robust to the choice of utility function. This robustness makes a strong case for our approach. Numerical examples illustrate the characteristics of the new approach. We analyze the optimal strategy, e.g. in terms of the more conventional, in the insurance context, objective of minimizing the probability of ruin. Finally, we calculate the intrinsic risk-free return of the model and we show that the principle of Markowitz-don't put all your eggs in one basket-does not hold in this setting.

LIU, X.; LIN, X. S. A subordinated Markov model for stochastic mortality. 105-127. In this paper we propose a subordinated Markov model for modelling stochastic mortality. The aging process of a life is assumed to follow a finite-state Markov process with a single absorbing state and the stochasticity of mortality is governed by a subordinating gamma process. We focus on the theoretical development of the model and have shown that the model exhibits many desirable 
properties of a mortality model and meets many model selection criteria laid out in A J G Cairns et al. (ASTIN Bulletin 36:79-120, 2006; Scandinavian Actuarial Journal 2:79-113, 2008). The model is flexible and fits either historical mortality data or projected mortality data well. We also explore applications of the proposed model to the valuation of mortality-linked securities. A general valuation framework for valuing mortality-linked products is presented for this model. With a proposed risk loading mechanism, we can make an easy transition from the physical measure to a risk-neutral measure and hence is able to calibrate the model to market information. The phase-type structure of the model allows us to apply the matrix-analytic methods that have been extensively used in ruin theory in actuarial science and queuing theory in operations research (see S Asmussen in Applied probability and queues. Wiley, New York, 1987; S Asmussen and $\mathrm{H}$ Albrecher in Ruin probabilities, 2nd ed. World Scientific Publishing, Singapore, 2010; M F Neuts in Matrix-geometrix solutions in stochastic models. Johns Hopkins University Press, Baltimore, 1981). As a result, many quantities of interest such as the distribution of future survival rates, prediction intervals, the term structure of mortality as well as the value of caps and floors on the survival index can be obtained analytically.

OLBRICHT, W. Tree-based methods: a useful tool for life insurance. 129-147. Life insurance faces a number of new challenges. This paper identifies some difficulties with techniques that are widely used to cope with these challenges. As an interesting alternative tree-based methods are suggested and discussed. In particular a "hybrid" approach (using regression trees for a classification situation) is proposed. The main advantage of this approach is its ease of interpretability and its inherent transparency. The method appears to be particularly suitable for the identification of the risk factors in complex situations like disability insurance.

ZIMMERMAN, P. L. Index clause: analytical properties and the capitalization strategy. 149-160. In non-life insurance, some bodily liability losses (e.g. loss of income) are paid out as annuity until specified age or death of victim. In case of excess of loss reinsurance, reinsurers often do not accept the inflation risk embedded in such losses and therefore include in the reinsurance treaty so called index clause which increases the priority by the impact of the inflation on the loss. A formula to calculate the expected reinsurance recoveries and its limiting behaviour in case of presence of the index clause is derived and illustrated. A capitalization strategy which minimizes the insurer's loss is derived.

Reproduced with the permission of Springer.

Subscription details available from:http://link.springer.com/contactus

http://link.springer.com/journal/13385

Geneva Papers on Risk and Insurance

$37(3), 2012$

BROWNE, M. J.; LU, L.; LEI, Y. Reinsurance purchases, contingent commission payments and insurer reserve estimation. 452-466. Prior studies on errors in reserve estimation suggest that insurers manage loss reserves to achieve corporate goals, including tax minimisation and income smoothing. Analysing U.S. property and casualty insurance industry data, we find a relationship between reserve errors and the purchase of reinsurance. A relationship is also found between reserve errors and the payment of contingent commissions. Since reserve errors may be costly in 
both instances, insurers who purchase reinsurance and those who pay contingent commissions may have a greater incentive to reserve accurately than other insurers. We find that in these cases insurers report smaller over-reserving errors.

CARTER, R. B.; POWER, M. L. Reputational signals and capital acquisition when insurance companies go public. 485-508. We analyse reputational signals and decisions surrounding capital acquisition by examining 76 insurance firms going public from 1996 to 2006 . We first explore the relationship between proxies for insurance firm reputation and initial public offering (IPO) underwriter reputation. In general, we find that more reputable underwriters market IPOs of more reputable insurers-insurers that are less risky, more likely to be life insurers and that have higher franchise value. These results suggest that underwriter and insurer reputations are aligned and send consistent signals. Second, we show that the market requires a higher return from riskier/less reputable insurers when they go public. When we compare the performance of our insurance company sample to a matched sample of non-insurance firms, we find that the greater reputational transparency of insurers allows the market to do a better job of determining future performance. Last, we conclude by showing empirically that franchise value and the reputational posture of the insurance firms are positively related. These results contribute to the growing body of knowledge on reputational risk management and should enhance capital acquisition strategies of insurance company managers.

D'ARCY, S. P.; LWIN, T. Optimal capital structure for a property-liability insurer. 509-538. Traditional finance studies have found that firm value is maximised at a mid-range level of leverage. This paper empirically tests the effect of leverage on firm value for property-liability insurers. We analysed an international data set of 96 insurers from 1992 to 2006 using two measures for firm value (price-to-earnings and market-to-book) and three measures of leverage (liabilities-to-equity, premiums-to-equity and surplus duration). We found that price-to-earnings at first increases with leverage, as measured by liabilities-to-equity and premiums-to-equity, but decreases past a certain point. Market-to-book exhibited a similar pattern for the premium-toequity ratio but had a positive relationship with liabilities-to-equity and a negative relationship with surplus duration.

GATZERT, N.; WESKER, H. A comparative assessment of Basel II/III and Solvency II. 539-570. In the course of creating a single European market for financial services and in the wake of two financial crises, regulatory frameworks in the financial services industry in the European Union have undergone significant change. One of the major reforms has been the transition from static rules-based systems towards principles-based regulation with the intent to better capture the risk situation of an undertaking. For insurance companies, the regulatory framework Solvency II is being finalised and is scheduled for implementation after 2013. At the same time, the regulatory regime for banking, Basel II, has been revised in response to the financial crisis; the new version is Basel III. The aim of this paper is to conduct a comprehensive and structured comparative assessment of Basel II/III and Solvency II in order to detect similarities and differences as well as the benefits and drawbacks of both regimes, which might be profitably addressed. The comparison is conducted against the background of the industries' characteristics and the objectives of regulation.

GUPTA, M.; PRAKASH, P. Information embedded in directors and officers insurance purchases. 429-451. We examine corporate purchases of Directors and Officers (D\&O) liability insurance and find that in addition to governance quality it contains managers' private information. 
In particular, we find that insider control in excess of insider share holdings is jointly associated with lower D\&O coverage limits and higher firm performance. The result holds when deductibles, corporate governance characteristics and litigation risk factors are controlled for. Our finding is consistent with an asymmetric information hypothesis in financial markets which posits that managers possess private information about firm risk. Our findings differ from existing literature that shows that D\&O insurance purchases primarily reflect firm's governance quality and litigation risk. The evidence supports the policy prescription advanced in earlier studies which call for mandatory public disclosure of $\mathrm{D} \& \mathrm{O}$ insurance purchases since it contains additional information for the market.

LEE, H.-H.; LEE, C.-Y. An analysis of reinsurance and firm performance: evidence from the Taiwan property-liability insurance industry. 467-484. This study investigates the relationship between reinsurance and firm performance by sourcing panel data from the 1999 to 2009 period of the property-liability insurance industry in Taiwan. The results of this investigation offer some insight that firm performance and reinsurance are interdependent. We find that insurers with higher return on assets (ROA) tend to purchase less reinsurance and insurers with higher reinsurance dependence tend to have a lower level of firm performance. Therefore, managers have to strike a balance between decreasing insolvency risk and reducing potential profitability. Other empirical results show that ROA, underwriting risks, liquidity ratio, business line concentration, return on investment (ROI) and financial holding dummy have a significant correlation with reinsurance. In addition, firm size, financial leverage, reinsurance, underwriting risks, liquidity ratio and ROI have a significant influence on firm performance. Our results have practical implications for the property-liability insurance industry and competent authorities in Taiwan.

SCHLÜTTER, S.; GRÜNDL, H. Who benefits from building insurance groups? A welfare analysis of optimal group capital management. 571-593. This paper compares the shareholder-valuemaximising capital structure and pricing policy of insurance groups against that of stand-alone insurers. Groups can utilise intra-group risk diversification by means of capital and risk transfer instruments. We show that using these instruments enables the group to offer insurance with less default risk and at lower premiums than is optimal for stand-alone insurers. We also take into account that shareholders of groups could find it more difficult to prevent inefficient overinvestment or cross-subsidisation, which we model by higher dead-weight costs of carrying capital. The trade-off between risk diversification on the one hand and higher dead-weight costs on the other can result in group-building being beneficial for shareholders but detrimental for policyholders.

ZHOU, C.; WU, C.; LI, D.; CHEN, Z. Insurance stock returns and economic growth. 405-428. In this paper, we propose to use insurance stock returns as an indicator of insurance activities, and apply a dynamic panel technique to examine the link between the role of insurance and economic growth. Our empirical results show that after we control for the variations of market index returns, there is a significantly positive relationship between insurance stock returns and future economic growth. Furthermore, we also investigate how law environment and governance quality affect the link between the role of insurance and economic growth. The empirical results are consistent with our expectation that a well-defined law environment and governance quality facilitate the functioning of insurance companies, and strengthen the role of insurance in economic growth. We find generally that the effect of law and governance on the link between the role of insurance and economic growth is more significant in developed markets than in emerging markets. 
Geneva Papers on Risk and Insurance

37(4), 2012

ATAGUBA, J. E.-O.; GOUDGE, J. The impact of health insurance on health-care utilisation and Out-of-Pocket payments in South Africa. 633-654. Health insurance is an alternative to direct out-of-pocket (OOP) financing. It aims to improve access to care and reduce direct OOP payments. However, this may not be the case if there is high cost sharing and limited cover. This paper uses the methodology of propensity score matching to investigate the impact of private insurance via membership of a medical scheme in South Africa on health-care utilisation and OOP payments. The paper finds that insurance coverage increases the use of private health services as would be expected but there is no significant effect on the use of public services. Further, such coverage does not result in lower OOP payments for scheme members compared to non-members. This calls for a need to design health insurance, in South Africa, in the form that not only ensures adequate utilisation of health services but also provides financial protection to the insured as reflected in the current commitment for a National Health Insurance.

BARROS, R. H.; TORRE-ENCISO, M. I. M. Operational losses for the capital charge of health insurers: lessons from Spain. 763-779. The new legislation in the insurance sector within the European Union, Solvency II, which represents an important milestone for the management and financial analysis of operational risk, will have a positive impact on their knowledge and control. This research explores the statistical analysis of the operational risks of health insurance companies in Spain from an external database of insured losses, which is a qualitative relevant aspect that will help to understand its behaviour for the future combination of data and the later selection of models and subsequent quantification of solvency capital. Results show that the database is consistent with the overall performance of operational risks, which ultimately will facilitate the acceptance and control of operational risks within insurers.

CONNELLY, L. B.; BUTLER, J. R. G. Insurance rebates, incentives and primary care in Australia. 745-762. Australia has a universal, compulsory, public health insurance scheme that includes insurance rebates for private fee-for-service medical practitioner services. Recent sweeping changes to the rebates for general practitioner (GP) services provide an opportunity to observe the effects of widespread insurance changes on the behaviour of GPs and aggregate outcomes such as quantities, prices and co-payments. In this paper, we study the effect of two important changes to subsidies for GP services, the first of which increased the rebates payable for services provided to specific patient groups, and the second of which increased rebates payable for all patients. Using economic theory, predictions of the effect of the rebate increase on quantities, prices and co-payments are produced that depend on the structure of the market. Using time-series data, we then present short-run empirical evidence that suggests that the supply curve for GP services is backward-bending.

COSTA-FONT, J.; MCGUIRE, A.; SERRA-SASTRE, V. The "Weisbrod Quadrilemma" revisited: insurance incentives on new health technologies. 678-695. The effect of insurance expansion on the diffusion of new technologies is not a well-understood phenomenon. Arguably, an expansion of insurance coverage provides a motivation for R\&D [research and development] investment in medical technologies. Although risk pooling through insurance gives rise to greater affordability for existing treatments and becomes a volume driver of new treatments, it may also influence provider reimbursement through a monopsony purchaser effect and related cost control 
measures. However, the impact that insurance has on technology availability and R\&D investment, and more generally on the adoption of new technologies, remains an unexplored empirical question. This paper presents evidence of a link between insurance and technology diffusion using OECD [Organisation for Economic Co-operation and Development] panel data and taking advantage of a dynamic specification structure. Our empirical estimates indicate that higher degrees of private expenditure on health care correlate with higher levels of R\&D in health care, consistent with the hypothesis forwarded by Weisbrod that increasing insurance coverage boosts technology adoption. However, our findings also suggest that increasing public funding of health care appears to lower technological adoption, which is, of course, consistent with the exercising of monopsony power and an objective of cost containment.

FELDMAN, R. Why do employers self-insure? New explanations for the choice of self-insurance vs. purchased health insurance. 696-711. This paper proposes that an employer's choice of selfinsurance vs. purchased health insurance can be explained by a trade-off between administrator moral hazard, the incentive for third-party administrators to be inefficient managers of selfinsured employers' medical claims and employer moral hazard, the insured employer's failure to invest in reducing health risks among its workers. These explanations have not been analysed in the literature but they are broadly consistent with data and they can explain the increasing popularity of self-insurance over the past 10 years.

GUILLÉN, M.; COMAS-HERRERA, A. How much risk Is mitigated by LTC protection schemes? A methodological note and a case study of the public system in Spain. 712-724. We present a methodology to measure the risk of incurring extremely large individual lifetime costs of long-term care (LTC). We show a method that can be used to compare the risk reductions achieved by alternative LTC protection plans. Our proposed methodology is illustrated with a case study. Our estimates show that, according to our proposed risk measure, the Spanish public LTC system mitigates individual risk by more than 30 per cent compared to the situation where no public protection is available. However, the Spanish public LTC system still leaves individuals facing very high lifetime costs of care. We estimate that there is a risk of about 1 per cent that a man will have to spend more than 211,800 and a risk of about 1 per cent that a woman will have to spend about 232,600 to cover lifetime LTC costs. Despite the current public Spanish LTC coverage, risk mitigation may still be too low since catastrophic costs of care persist and, therefore, we suggest that private insurance should be encouraged.

ROBSON, A.; PAOLUCCI, F. Private health insurance incentives in Australia: the effects of recent changes to price carrots and income sticks. 725-744. Three major policy tools govern the demand for private health insurance (PHI) in Australia: premium-related subsidies (i.e. PHI-rebate); income tax surcharges (i.e. the Medicare Levy Surcharge (MLS)); and lifetime community-rating (i.e. Lifetime Health Cover). The first two provide a system of "carrots and sticks" to create incentives for increasing the demand for PHI. The third creates incentives for consumers to purchase PHI earlier than they otherwise would have, and to maintain this coverage over time even when prices rise. This paper makes a number of contributions to the existing literature. We develop a diagrammatic model that incorporates income heterogeneity and use it to consider two important policy issues: the effect of policy changes on consumer price responsiveness, and the effect of policy changes on the PHI take-up rates. The model suggests that recent changes to the income tax surcharge are likely to reduce the price elasticity of demand for insurance, which could have further consequences for outcomes in the PHI market and the health system more generally. Increases in premiums will reduce take-up, but could worsen the government's budget position, even if tax revenues were to rise. Finally, we conduct numerical simulations to examine 
the possible effects of recent policy changes, which are aimed at further means-testing the PHI rebate and the MLS. The simulation results suggest that these recently adopted policy changes are likely to reduce the take-up of PHI as well as consumers' responsiveness to future premium increases.

ROLL, K.; STARGARDT, T.; SCHREYÖGGA, J. Effect of type of insurance and income on waiting time for outpatient care. 609-632. This paper analyses the impact of type of insurance, income and reason for appointment on waiting time for an appointment and waiting time in the physician's practice in the outpatient sector. Data was obtained from a German patient survey conducted between 2007 and 2009. We differentiated between general practitioner (GP) and specialist and controlled for socioeconomic, structural and institutional characteristics as well as interactions between type of insurance and control variables. Our results reveal that private health insurance plays a significant role in faster access to care at GP and specialist practices. Access to care is also highly influenced by the reason for an appointment. We also found that increased income had a negative effect on waiting time in practices and on waiting time for an appointment in GP practices. Whether inequalities in access to health care also impact overall quality of treatment needs to be investigated in future research.

TIAN, W.-H.; TIEN, J. J.; CHEN, C.-S.; LIU, T.-C. Private health insurance and in-patient service utilisation among adults and elderly people under Taiwan's National Insurance Programme. 655-677. Previous studies have shown that demand for the quantity of medical services has increased since the implementation of the National Health Insurance (NHI) programme. This paper extends the investigation to the relationship between private health insurance and inpatient service utilisation under the NHI programme in Taiwan. By using nationwide population-based claim data, we utilise a two-part model to investigate whether individuals with private health insurance have higher probabilities of utilising inpatient services. We further examine the effect of those individuals with private health insurance on the inpatient length of stay for those utilising inpatient services. The results indicate that individuals with private health insurance are more likely to use inpatient services and spend more days in a hospital compared to those without private health insurance. We propose that this finding provides a good reference for government and insurance companies when formulating relevant health insurance policies.

Reproduced with the permission of Palgrave MacMillan.

Subscription details available from: Palgrave Macmillan Subscription Department Tel: +44 (0)1256 357893, subscriptions@palgrave.com

http://www.palgrave-journals.com/pal/subscribe/index.html

Geneva Risk and Insurance Review

$37(2), 2012$

BIENVENUE, A.; RULLIÈRE, D. Iterative adjustment of survival functions by composed probability distortion. 156-179. We introduce a parametric class of composite probability distortions that can be combined to converge to a target survival function. These distortions respect analytic invertibility and stability, which are shown to be relevant in many actuarial fields. We study the asymptotic impact of such distortions on hazard rates. The paper provides an estimation methodology, including hints for initialisation. Some applications to survival data bring results for catastrophic event impact modelling. We also obtain accurate parametric 
representations of the mortality trend over years. Finally, we suggest a prospective mortality simulation model that comes naturally from the above analysis.

CARDON, J. H. Health insurance choice with flexible spending accounts. 208-222. I model the interaction of flexible spending accounts (FSAs) and conventional insurance. I show that FSA participation reduces the desired level of insurance coverage. I also show that FSA participation can reduce the total tax cost of health insurance premium and FSA contribution exclusions.

CHANG, C.-H.; LEE, C.-CG. Non-linearity between life insurance and economic development: a revisited approach. 223-257. This paper investigates the non-linear link between economic development and activities of the life insurance market. We ask whether the relevance of institutional environments on the development of the life insurance market is different across countries. Applying a novel threshold model with the instrumental variable approach, we find overwhelming evidence in support of an income threshold. Moreover, legal and political circumstances have an overwhelming positive effect on life insurance in low-income countries, but the effect is marginal in high-income countries. Our findings clearly demonstrate that the role of institutions on activities in the life insurance market diminishes with the evolvement of economic development.

EECKHOUDT, L. Beyond risk aversion: Why, how and what's next?: EGRIE Keynote Address. 141-155. Risk attitudes other than risk aversion (e.g. prudence and temperance) are becoming important both in theoretical and empirical work. While the literature has mainly focused its attention on the intensity of such risk attitudes (e.g. the concepts of absolute prudence and absolute temperance), I consider here an alternative approach related to the direction of these attitudes (i.e. the sign of the successive derivatives of the utility function).

ELING, M.; SCHMIT, J. T. Is there market discipline in the European insurance industry?: An analysis of the German insurance market. 180-207. Economists often argue in favour of market discipline as a means to distribute resources effectively and efficiently. These same arguments likely influence decision-makers as they incorporate market discipline as the third pillar of Solvency II, the European insurance regulatory scheme currently being implemented. Success for Solvency II, then, is dependent in part on the strength of influence found in market discipline. Our research indicates that the German insurance market demonstrates the existence of such discipline, although the actual effect appears smaller than previously found in the U.S. insurance market. Solvency II, therefore, seems to be following an appropriate path, although further research is needed to evaluate whether or not enhancements to market discipline within the European market are warranted.

HUANG, R. J.; SHIH, P.-T.; TZENG, L. Y. Disappointment and the optimal insurance contract. 258-284. This paper studies the optimal insurance contract under disappointment theory. We show that, when the individuals anticipate disappointment, there are two types of optimal insurance contract. The first type contains a deductible and a coinsurance above the deductible. We find that zero marginal cost is just a sufficient but not a necessary condition for a zero deductible. The second type has no deductible and the optimal insurance starts with full coverage for small losses and includes a coinsurance above an upper value of the full coverage.

Reproduced with the permission of Palgrave MacMillan.

Subscription details available from: Palgrave Macmillan Subscription Department Tel: +44 (0)1256 357893, subscriptions@palgrave.com

http://www.palgrave-journals.com/pal/subscribe/index.html 
Insurance: Mathematics \& Economics

$51(2), 2012$

AVANZI, B.; WONG, B. On a mean reverting dividend strategy with Brownian motion. 229-238. In actuarial risk theory, the introduction of dividend pay-outs in surplus models goes back to de Finetti (1957). Dividend strategies that can be found in the literature often yield pay-out patterns that are inconsistent with actual practice. One issue is the high variability of the dividend payment rates over time. We aim at addressing that problem by specifying a dividend strategy that yields stable dividend pay-outs over time. In this paper, we model the surplus of a company with a Brownian risk model. Dividends are paid at a constant rate g of the company's modified surplus (after distribution of dividends), which operates as a buffer reservoir to yield a regular flow of shareholders' income. The dividend payment rate reverts around the drift of the original process $\mu$, whereas the modified surplus itself reverts around the level $l=\mu / \mathrm{g}$. We determine the distribution of the present value of dividends when the surplus process is never absorbed. After introducing an absorbing barrier a (inferior to the initial surplus) and stating the Laplace transform of the time of absorption, we derive the expected present value of dividends until absorption. The latter is then also determined if dividends are not paid whenever the surplus is too close to the absorbing barrier. The calculation of the optimal value of the parameter 1 (and equivalently g) is discussed. We conclude by comparing both barrier and mean reverting dividend strategies.

BALLESTRA, L. V.; OTTAVIANI, M.; PACELLI, G. An operator splitting harmonic differential quadrature approach to solve Young's model for life insurance risk. 442-448. This paper is concerned with the numerical approximation of a mathematical model for life insurance risk that has been presented quite recently by [Young, 2007] and [Young, 2008] [V.R. Young (2008), Pricing life insurance under stochastic mortality via the instantaneous Sharpe ratio, Insurance: Mathematics and Economics, 42: 691-703]. In particular, such a model, which consists of a system of several non-linear partial differential equations, is solved using a new numerical method that combines an operator splitting procedure with the differential quadrature (DQ) finite difference scheme. This approach allows one to reduce the partial differential problems to systems of linear equations of very small dimension, so that pricing portfolios of many life insurances becomes a relatively easily task. Numerical experiments are presented showing that the method proposed is very accurate and fast. In addition, the limit behaviour of portfolios of life insurances as the number of contracts tends to infinity is investigated. This analysis reveals that the prices of portfolios comprising more than five thousand policies can be accurately approximated by solving a linear partial differential equation derived in [Young, 2007] and [Young, 2008].

BELZUNCE, F.; PINAR, J. F.; RUIZ, J. M.; SORDO, M. A. Comparison of risks based on the expected proportional shortfall. 292-302. In this paper, we consider a new criterion to compare risks based on the notion of expected proportional shortfall. This criterion is useful for comparing risks of different nature and does not depend on the base currency. We study its relationships with other criteria and provide some characterizations that highlight the role of this new criterion in the context of comparisons of risks.

CHEN, Y.; YUEN, K. C. Precise large deviations of aggregate claims in a size-dependent renewal risk model. 457-461. Consider a renewal risk model in which claim sizes and inter-arrival times correspondingly form a sequence of independent and identically distributed random pairs, with 
each pair obeying a dependence structure described via the conditional distribution of the interarrival time given the subsequent claim size being large. We study large deviations of the aggregate amount of claims. For a heavy-tailed case, we obtain a precise large-deviation formula, which agrees with existing ones in the literature.

CHI, Y. Optimal reinsurance under variance related premium principles. 310-321. In this paper, we investigate the optimal form of reinsurance when the insurer seeks to minimize the value at risk $(\mathrm{VaR})$ or the conditional value at risk $(\mathrm{CVaR})$ of his/her total risk exposure. In order to exclude the moral hazard from a reinsurance treaty, both the ceded and retained loss functions are constrained to be increasing. Under the additional assumption that the reinsurance premium is calculated by a variance related principle, we show that the layer reinsurance is always optimal over both the VaR and CVaR criteria. Finally, the variance and standard deviation premium principles are applied to illustrate how to derive the optimal deductible and the upper limit of layer reinsurance.

COSSETTE, H.; LANDRIAUlT, D.; MARCEAU, E.; MOUTANABBIR, K. Analysis of the discounted sum of ascending ladder heights. 393-401. Within the Sparre Andersen risk model, the ruin probability corresponds to the survival function of the maximal aggregate loss. It is well known that the maximum aggregate loss follows a compound geometric distribution, in which the summands consist of the ascending ladder heights. In the present paper, we propose to investigate the distribution of the discounted sum of ascending ladder heights over a finite or an infinite-time intervals. In particular, the moments of the discounted sum of ascending ladder heights over a finite and an infinite-time intervals are derived in both the classical compound Poisson risk model and the Sparre Andersen risk model with exponential claims. The application of a particular Gerber-Shiu functional is central to the derivation of these results, as is the mixed Erlang distributional assumption. Finally, we define VaR and TVaR risk measures in terms of the discounted sum of ascending ladder heights. We use a moment-matching method to approximate the distribution of the discounted sum of ascending ladder heights allowing the computation of the VaR and TVaR risk measures. We conclude this paper with a numerical example illustrating different topics discussed in the paper.

DENUIT, M.; DHAENE, J. Convex order and comonotonic conditional mean risk sharing. 265-270. Using a standard reduction argument based on conditional expectations, this paper argues that risk sharing is always beneficial (with respect to convex order or second degree stochastic dominance) provided the risk-averse agents share the total losses appropriately (whatever the distribution of the losses, their correlation structure and individual degrees of risk aversion). Specifically, all agents hand their individual losses over to a pool and each of them is liable for the conditional expectation of his own loss given the total loss of the pool. We call this risk sharing mechanism the conditional mean risk sharing. If all the conditional expectations involved are non-decreasing functions of the total loss then the conditional mean risk sharing is shown to be Pareto-optimal. Explicit expressions for the individual contributions to the pool are derived in some special cases of interest: independent and identically distributed losses, comonotonic losses, and mutually exclusive losses. In particular, conditions under which this payment rule leads to a comonotonic risk sharing are examined.

DHAENE, J.; GOOVAERTS, M.; VANMAELE, M.; VAN WEERT, K. Convex order approximations in the case of cash flows of mixed signs. 249-256. In Van Weert et al. (2010) [K Van Weert, J Dhaene, M Goovaerts, Optimal portfolio selection for general provisioning and terminal wealth 
problems, Insurance: Mathematics and Economics, 47 (1) (2010): 90-97], results are obtained showing that, when allowing some of the cash flows to be negative, convex order lower bound approximations can still be used to solve general investment problems in a context of provisioning or terminal wealth. In this paper, a correction and further clarification of the reasoning of Van Weert et al. (2010) are given, thereby significantly expanding the scope of problems and cash flow patterns for which the terminal wealth or initial provision can be accurately approximated. Also an interval for the probability level is derived in which the quantiles of the lower bound approximation can be computed. Finally, it is shown how one can move from a context of provisioning of future obligations to a saving and terminal wealth problem by inverting the time axis.

ELING, M. Fitting insurance claims to skewed distributions: are the skew-normal and skew-student good models? 239-248. This paper analyzes whether the skew-normal and skew-student distributions recently discussed in the finance literature are reasonable models for describing claims in property-liability insurance. We consider two well-known datasets from actuarial science and fit a number of parametric distributions to these data. Also the non-parametric transformation kernel approach is considered as a benchmark model. We find that the skewnormal and skew-student are reasonably competitive compared to other models in the literature when describing insurance data. In addition to goodness-of-fit tests, tail risk measures such as value at risk and tail value at risk are estimated for the datasets under consideration.

FENG, R.; VOLKMER, H. W. Modelling credit value adjustment with downgrade-triggered termination clause using a ruin theoretic approach. 409-421. Downgrade-triggered termination clause is a recent innovation in credit risk management to control counterparty credit risk. It allows one party of an over-the-counter derivative to close off its position at marked-to-market price when the other party's credit rating downgrades to an agreed alarming level. Although the default risk is significantly reduced, the non-defaulting party may still suffer losses in case that the other party defaults without triggering the termination clause prior to default. At the heart of the valuation of credit risk adjustment (CVA) is the computation of the probability of default. We employ techniques from ruin theory and complex analysis to provide solutions for probabilities of default, which in turn lead to very efficient and accurate algorithms for computing CVA. The underlying risk model in question is an extension of the commercially available KMV-Merton model and hence can be easily implemented. We provide a hypothetical example of CVA computation for an interest-rate swap with downgrade-triggered termination clause. The paper also contributes to ruin theory by presenting some new results on finite-time ruin probabilities in a jump-diffusion risk model.

GRIFFIN, P. S.; MALLER, R. A.; VAN SCHAIK, K. Asymptotic distributions of the overshoot and undershoots for the Lévy insurance risk process in the Cramér and convolution equivalent cases. 382-392. Recent models of the insurance risk process use a Lévy process to generalise the traditional Cramér-Lundberg compound Poisson model. This paper is concerned with the behaviour of the distributions of the overshoot and undershoots of a high level, for a Lévy process which drifts to $-\infty$ and satisfies a Cramér or a convolution equivalent condition. We derive these asymptotics under minimal conditions in the Cramér case, and compare them with known results for the convolution equivalent case, drawing attention to the striking and unexpected fact that they become identical when certain parameters tend to equality. Thus, at least regarding these quantities, the "medium-heavy" tailed convolution equivalent model segues into the "light-tailed" Cramér model in a natural way. This suggests a usefully expanded flexibility for modelling the 
insurance risk process. We illustrate this relationship by comparing the asymptotic distributions obtained for the overshoot and undershoots, assuming the Lévy process belongs to the "GTSC" class.

HUA, L.; JOE, H. Tail comonotonicity: properties, constructions, and asymptotic additivity of risk measures. 472-479. We investigate properties of a version of tail comonotonicity that can be applied to absolutely continuous distributions, and give several methods for constructions of multivariate distributions with tail comonotonicity or strongest tail dependence. Archimedean copulas as mixtures of powers, and scale mixtures of a non-negative random vector with the mixing distribution having slowly varying tails, lead to a tail comonotonic dependence structure. For random variables that are in the maximum domain of attraction of either Fréchet or Gumbel, we prove the asymptotic additivity property of Value at Risk and Conditional Tail Expectation.

HUANG, H.; MILEVSKY, M. A.; SALISBURY, T. S. Optimal retirement consumption with a stochastic force of mortality. 282-291. We extend the lifecycle model (LCM) of consumption over a random horizon (also known as the Yaari model) to a world in which (i) the force of mortality obeys a diffusion process as opposed to being deterministic, and (ii) consumers can adapt their consumption strategy to new information about their mortality rate (also known as health status) as it becomes available. In particular, we derive the optimal consumption rate and focus on the impact of mortality rate uncertainty versus simple lifetime uncertainty - assuming that the actuarial survival curves are initially identical - in the retirement phase where this risk plays a greater role. In addition to deriving and numerically solving the partial differential equation (PDE) for the optimal consumption rate, our main general result is that when the utility preferences are logarithmic the initial consumption rates are identical. But, in a constant relative risk aversion (CRRA) framework in which the coefficient of relative risk aversion is greater (smaller) than one, the consumption rate is higher (lower) and a stochastic force of mortality does make a difference. That said, numerical experiments indicate that, even for non-logarithmic preferences, the stochastic mortality effect is relatively minor from the individual's perspective. Our results should be relevant to researchers interested in calibrating the lifecycle model as well as those who provide normative guidance (also known as financial advice) to retirees.

KALUSZKA, M.; LAEVEN, R. J. A.; OKOLEWSKI, A. A note on weighted premium calculation principles. 379-381. A prominent problem in actuarial science is to determine premium calculation principles that satisfy certain criteria. Goovaerts et al. [Goovaerts, M. J., De Vylder, F., Haezendonck, J., (1984). Insurance Premiums: Theory and Applications. North-Holland, Amsterdam, p. 84] establish an optimality-type characterization of the Esscher premium principle, but unfortunately their result is not true. In this note we propose a modified statement of this result.

LANDRIAULT, D.; LEMIEUX, C.; WILLMOT, G. E. An adaptive premium policy with a Bayesian motivation in the classical risk model. 370-378. In this paper, we consider an extension of the classical risk model in which the premium rate policy is adaptive to claim experience. We assume that the premium rate is reviewed each time the surplus reaches a new descending ladder height. A choice between a finite number $\mathrm{m}$ of rates is then made depending on the time elapsed between successive ladder heights. We derive explicit expressions for the probability of ruin in this model, assuming claim sizes have a mixed Erlang distribution. We then motivate further the idea behind this adaptive premium rate policy by using a mixed Poisson process for the claim arrival, and propose a method to fix the parameters of the policy in this setting. Finally, we discuss other applications of this method. 
LEE, Y.-T.; WANG, C.-W.; HUANG, H.-C. On the valuation of reverse mortgages with regular tenure payments. 430-441. For the valuation of reverse mortgages with tenure payments, this article proposes a specific analytic valuation framework with mortality risk, interest rate risk, and housing price risk that helps determine fair premiums when the present value of premiums equals the present value of contingent losses. The analytic valuation of reverse mortgages with tenure payments is more complex than the valuation with a lump sum payment. This study therefore proposes a dimension reduction technique to achieve a closed-form solution for reverse annuity mortgage insurance, conditional on the evolution of interest rates. The technique provides strong accuracy, offering important implications for lenders and insurers.

LIN, J. Second order asymptotics for ruin probabilities in a renewal risk model with heavy-tailed claims. 422-429. In this paper, we establish the second order asymptotics of ruin probabilities of a renewal risk model under the condition that the equilibrium distribution of claim sizes belongs to a rather general heavy-tailed distribution subclass-the class of second order subexponential distributions with finite mean. What is more, this requirement is proved to be necessary. Furthermore, a rather general sufficient condition on the claim size distribution itself is presented. Moreover, an extension to the case of random walk is also included.

LÓPEZ-DÍAZ, M.; SORDO, M. A.; SUÁREZ-LLORENS, A. On the $L_{p}$-metric between a probability distribution and its distortion. 257-264. In actuarial theory, the $L_{p}$-metric is used to evaluate how well a probability distribution approximates another one. In the context of the distorted expectation hypothesis, the actuary replaces the original probability distribution by a distorted probability, so it makes sense to interpret the $L_{p}$-metric between them as a characteristic of the underlying random variable. We show in this paper that this is a characteristic of the variability of the random variable, study its properties and give some applications.

LU, Z.; LIU, L.; MENG, L. Optimal insurance under multiple sources of risk with positive dependence. 462-471. In this paper we try to derive an optimal insurance treaty when the insured faces multiple sources of risk. We show that the deductible insurance is optimal when the insurable and uninsurable risks are positively dependent or independent within the expected utility framework. A necessary condition of optimal deductible is given under some mild conditions. We compare our model with the classical one without background risk. Furthermore, the shifts of optimal deductible and expected utility by modifications of the dependence structure and the marginal are analyzed.

MAO, T.; LV, W.; HU, T. Second-order expansions of the risk concentration based on CTE [Conditional Tail Expectation]. 449-456. The quantification of diversification benefits due to risk aggregation has received more attention in the recent literature. In this paper, we establish second-order expansions of the risk concentration based on the risk measure of conditional tail expectation [CTE] for a portfolio of $\mathrm{n}$ independent and identically distributed loss random variables. The key tools are the theory of second-order regular variation and the theory of secondorder subexponentiality. Some examples are given.

MAO, T.; HU, T Second-order properties of the Haezendonck-Goovaerts risk measure for extreme risks. 333-343. The Haezendonck-Goovaerts risk measure is based on the premium calculation principle induced by an Orlicz norm, which is defined via an increasing and convex Young function and a parameter $q \in(0,1)$ representing the confidence level. In this paper, we first re-establish the first-order expansions of the Haezendonck-Goovaerts risk measure for extreme 
risks with a power Young function in Q Tang and F Yang (2012) [On the HaezendonckGoovaerts risk measure for extreme risks, Insurance: Mathematics and Economics, 50 (2012), pp. 217-227] in terms of the tail quantile function. Second, we are interested in the calculation of the second-order expansions of the Haezendonck-Goovaerts risk measure as $q \uparrow 1$. We only consider the case in which the risk variable belongs to the max-domain of attraction of an extreme value distribution.

PESTA, M.; HUDECOVÁ, S. Asymptotic consistency and inconsistency of the chain ladder. 472-479. The distribution-free chain ladder reserving method belongs to the most frequently used approaches in general insurance. It is well known, see Mack (1993), [T. Mack (1993), Distribution-free calculation of the standard error of chain ladder reserve estimates, ASTIN Bulletin 23(2): 213-225] that the estimators $\hat{f}_{j}$ of the development factors are unbiased and mutually uncorrelated under some mild conditions on the mean structure and under the assumption of independence of the claims in different accident years. In this article we deal with some asymptotic properties of necessary and sufficient conditions for asymptotic consistency of the estimators of true development factors $\hat{f}_{j}$ are provided. A rate of convergence for the consistency is derived. Possible violation of these conditions and its consequences are discussed, and some practical recommendations are given. Numerical simulations and a real data example are provided as well.

PIRVU, T. A.; ZHANG, H. Optimal investment, consumption and life insurance under meanreverting returns: the complete market solution. 303-309. This paper considers the problem of optimal investment, consumption and life insurance acquisition for a wage earner who has CRRA (constant relative risk aversion) preferences. The market model is complete, continuous, the uncertainty is driven by Brownian motion and the stock price has mean reverting drift. The problem is solved by dynamic programming approach and the HJB [Hamilton-Jacobi-Bellman] equation is shown to have closed form solution. Numerical experiments explore the impact market price of risk has on the optimal strategies.

REN, J. A multivariate aggregate loss model. 402-408. In this paper, we introduce a multivariate aggregate loss model, where multiple categories of losses are considered. The model assumes that different types of claims arrive according to a Marked Markovian arrival process (MMAP) introduced by He and Neuts (1998) [Q M He, M F Neuts (1998), Markov chains with marked transitions, Stochastic Processes and their Applications 74: 37-52] in the queuing literature. This approach enables us to allow dependencies among the claim frequencies, and among the claim sizes, as well as between claim frequencies and claim sizes. This model extends the (univariate) Markov modulated risk processes (sometimes referred to as regime switching models) widely used in insurance and financial analysis. For the proposed model, we provide formulas for calculating the joint moments of the present value of aggregate claims occurring in any time interval $(0, t]$. Numerical examples are provided to show possible applications of the model.

SU, S.; SHERRIS, M. Heterogeneity of Australian population mortality and implications for a viable life annuity market. 322-332. Heterogeneity in mortality rates is known to exist in populations, undermining the use of age and sex as the only rating factors for life insurance and annuity products. Life insurers offering life annuities assume that annuitant lives will self-select, and price the longevity risk with an annuity mortality table that assumes above-average longevity. This leads to annuities being less attractive to a wide range of individuals, and limits the viability of private annuity markets. This paper quantifies heterogeneity and its financial implications for 
annuity prices using well-established frailty models and a more recently developed Markov ageing model calibrated to population mortality data. The heterogeneity implied for each model is quantified using Australian population mortality. The models are compared by considering the distribution of heterogeneity by age implied by the models and the implications for life annuity prices.

VILLEGAS, A. M.; MEDAGLIA, A. L.; ZULUAGA, L. F. Computing bounds on the expected payoff of Alternative Risk Transfer products. 271-281. The demand for integrated risk management solutions and the need for new sources of capital have led to the development of innovative risk management products that mix the characteristics of traditional insurance and financial products. Such products, usually referred as Alternative Risk Transfer (ART) products include: (re)insurance contracts that bundle several risks under a single policy; multi-trigger products where the payment of benefits depends upon the occurrence of several events; and insurance linked securities that place insurance risks in the capital market. Pricing of these complex products usually requires tailor-made complex valuation methods that combine derivative pricing and actuarial science techniques for each product, as well as strong distributional assumptions on the ART's underlying risk factors. We present here an alternative methodology to compute bounds on the price of ART products when there is limited information on the distribution of the underlying risk factors. In particular, we develop a general optimizationbased method that computes upper and lower price bounds for different ART products using market data and possibly expert information about the underlying risk factors. These bounds are useful when the structure of the product is too complex to develop analytical or simulation valuation methods, or when the scarcity of data makes it difficult to make strong distributional assumptions on the risk factors. We illustrate our results by computing bounds on the price of a floating retention insurance contract, and a catastrophe equity put (CatEPut) option.

WANG, T.; YOUNG, V. R. Maximizing the utility of consumption with commutable life annuities. 352-369. The purpose of this paper is to reveal the relation between commutability of life annuities and retirees' willingness to annuitize. To this end, we assume the existence of commutable life annuities, whose surrender charge is a proportion of their actuarial value. We model a retiree as a utility-maximizing economic agent who can invest in a financial market with a risky and a riskless asset and who can purchase or surrender commutable life annuities. We define the wealth of an individual as the total value of her risky and riskless assets, which is required to be non-negative during her lifetime. We exclude the actuarial value of her annuity income in calculating wealth; therefore, we do not allow the individual to borrow from her future annuity income because this income is contingent on her being alive. We solve this incompletemarket utility maximization problem via duality arguments and obtain semi-analytical solutions. We find that the optimal annuitization strategy depends on the size of proportional surrender charge, with lower proportional surrender charges leading to more annuitization. We also find that full annuitization is optimal when there is no surrender charge or when the retiree is very risk averse. Surprisingly, we find that in the case for which the proportional surrender charge is larger than a critical value, it is optimal for the retiree to behave as if annuities are not commutable. We provide numerical examples to illustrate our results.

YE, J.; LI, T. The optimal mean-variance investment strategy under value-at-riskconstraints. 344-351. This paper is devoted to study the effects arising from imposing a value-at-risk (VaR) constraint in the mean-variance portfolio selection problem for an insurer who receives a stochastic cash flow which he must then invest in a continuous-time financial market. For simplicity, we assume that there is only one investment opportunity available for the insurer, 
a risky stock. Using techniques of stochastic linear-quadratic (LQ) control, the optimal meanvariance investment strategy with and without the VaR constraint is derived explicitly in closed forms, based on the solution of the corresponding Hamilton-Jacobi-Bellman (HJB) equation. Furthermore, a numerical example is proposed to show how the addition of the VaR constraint affects the optimal strategy.

ZHAO, X.; ZHOU, X. Estimation of medical costs by copula models with dynamic change of health status. 472-479. This paper develops models aimed at more accurate estimation of the medical cost function based on the individual cost data. In our proposed models, the cost data are assumed to be dependent on the whole clinical evolution via Markov transition probabilities, and the accumulative rate of cost in a time period (sojourn) has a semiparametric structure. The medical costs are recurrent at different time points with different states under informative censoring, and the cost incurred in a sojourn at a state is correlated with that sojourn. A copula is used to model the relationship between a sojourn and its associated cost. The multivariate local likelihood method is employed to estimate model parameters and the asymptotic properties of the estimators are established as well. Our methods can be easily extended to model the total cost and to analyze the cost-effectiveness of the model. Simulations are performed to assess the proposed models and methodology, and comparisons with certain existing models are discussed.

Insurance: Mathematics \& Economics

$51(3), 2012$

BERNARDI, M.; MARUOTTI, A.; PETRELLA, L. Skew mixture models for loss distributions: a Bayesian approach. 617-623. The derivation of loss distribution from insurance data is a very interesting research topic but at the same time not an easy task. To find an analytic solution to the loss distribution may be misleading although this approach is frequently adopted in the actuarial literature. Moreover, it is well recognized that the loss distribution is strongly skewed with heavy tails and presents small, medium and large size claims which hardly can be fitted by a single analytic and parametric distribution. Here we propose a finite mixture of Skew Normal distributions that provides a better characterization of insurance data. We adopt a Bayesian approach to estimate the model, providing the likelihood and the priors for the all unknown parameters; we implement an adaptive Markov Chain Monte Carlo algorithm to approximate the posterior distribution. We apply our approach to a well known Danish fire loss data and relevant risk measures, such as Value-at-Risk and Expected Shortfall probability, are evaluated as well.

D’AMATO, V.; HABERMAN, S.; PISCOPO, G.; RUSSOLILLO, M. Modelling dependent data for longevity projections. 694-701. The risk profile of an insurance company involved in annuity business is heavily affected by the uncertainty in future mortality trends. It is problematic to capture accurately future survival patterns, in particular at retirement ages when the effects of the rectangularization phenomenon and random fluctuations are combined. Another important aspect affecting the projections is related to the so-called cohort-period effect. In particular, the mortality experience of countries in the industrialized world over the course of the twentieth century would suggest a substantial age-time interaction, with the two dominant trends affecting different age groups at different times. From a statistical point of view, this indicates a dependence structure. Also the dependence between ages is an important component in the modelling of mortality (Barrieu et al., 2011 [P. Barrieu et al., (2011), Understanding, modelling 
and managing longevity risk: key issues and main challenges, Scandinavian Actuarial Journal 2012(3), 1-29]). It is observed that the mortality improvements are similar for individuals of contiguous ages (Wills and Sherris, 2008 [Wills, S.; Sherris, M.(2008), Integrating financial and demographic longevity risk models: an Australian model for financial applications. Pension Institute Discussion Paper, 0817, 1, p. 12]). Moreover, considering the data subdivided by set by single years of age, the correlations between the residuals for adjacent age groups tend to be high (as noted in Denton et al., 2005 [F.T Denton, C.H. Feaver, B.G. Spencer (2005), Time series analysis and stochastic forecasting: an econometric study of mortality and life expectancy, Journal of Population Economics, 18, 203-227]). This suggests that there is value in exploring the dependence structure, also across time, in other words the inter-period correlation. The aim of this paper is to improve the methodology for forecasting mortality in order to enhance model performance and increase forecasting power by capturing the dependence structure of neighbouring observations in the population. To do this, we adapt the methodology for measuring uncertainty in projections in the Lee-Carter context and introduce a tailor-made bootstrap instead of an ordinary bootstrap. The approach is illustrated with an empirical example.

\section{DEL BRIO, E. B.; PEROTE, J. Gram-Charlier densities: maximum likelihood Versus the method of} moments. 531-537. This paper compares two alternative estimation methods for estimating the density underlying financial returns specified in terms of a finite Gram-Charlier (GC) expansion. Maximum likelihood (ML) is the most widely employed method despite the fact that it is only consistent under the Gaussian or the true density, and usually involves convergence problems. Alternatively, the method of moments $(\mathrm{MM})$ is a natural and straightforward procedure, although positivity is only guaranteed in the asymptotic expansion. We show an example for estimating daily returns of the Dow Jones Index with a very long data set, illustrating that both ML and MM yield similar outcomes. Therefore the MM applied to GC densities should be considered as an accurate tool for risk management and forecasting.

FENG, R.; VOLKMER, H. W. Analytical calculation of risk measures for variable annuity guaranteed benefits. 636-648. With the increasing complexity of investment options in life insurance, more and more life insurers have adopted stochastic modelling methods for the assessment and management of insurance and financial risks. The most prevalent approach in market practice, Monte Carlo simulation, has been observed to be time consuming and sometimes extremely costly. In this paper we propose alternative analytical methods for the calculation of risk measures for variable annuity guaranteed benefits on a stand-alone basis. The techniques for analytical calculations are based on the study of geometric Brownian motion and its integral. Another novelty of the paper is to propose a quantitative model which assesses both market risk on the liability side and revenue risk on the asset side in the same framework from the viewpoint of risk management. As we demonstrate by numerous examples on quantile risk measure and conditional tail expectation, the methods and numerical algorithms developed in this paper appear to be both accurate and computationally efficient.

GAO, J.; ULM, E. R. Optimal consumption and allocation in variable annuities with Guaranteed Minimum Death Benefits. 586-598. We determine the optimal allocation of funds between the fixed and variable subaccounts in a variable annuity with a GMDB (Guaranteed Minimum Death Benefit) clause featuring partial withdrawals by using a utility-based approach. The Merton method is applied by assuming that individuals allocate funds optimally in order to maximize the expected utility of lifetime consumption. It also reflects bequest motives by including the recipient's utility in terms of the policyholder's guaranteed death benefits. We derive the optimal 
transfer choice by the insured, and furthermore price the GMDB through maximizing the discounted expected utility of the policyholders and beneficiaries by investing dynamically in the fixed account and variable fund and withdrawing optimally.

GATZERT, N.; MARTIN, M. Quantifying credit and market risk under Solvency II: standard approach versus internal model. 646-666. Even though insurers predominantly invest in bonds, credit risk associated with government and corporate bonds has long not been a focus in their risk management. After the crisis of several European countries, however, credit risk has recently been paid greater attention. Nevertheless, the latest version of the Solvency II standard model (QIS 5), provided by regulators for deriving solvency capital requirements, still does not require capital for credit risk inherent in, e.g., EEA issued government bonds from Greece or Spain. This paper aims to provide an alternative approach and compares the standard model with a partial internal risk model using a rating-based credit risk model that accounts for credit, equity, and interest rate risk inherent in a portfolio of stocks and bonds. The findings demonstrate that solvency capital requirements strongly depend on the quality and composition of an insurer's asset portfolio and that model risk in regard to model choice and calibration plays an important role in the quantification.

GU, A.; GUO, X.; LI, Z.; ZENG, Y. Optimal control of excess-of-loss reinsurance and investment for insurers under a CEV model. 674-684. The optimal excess-of-loss reinsurance and investment strategies under a constant elasticity of variance $(\mathrm{CEV})$ model for an insurer are considered in this paper. Assume that the insurer's surplus process is approximated by a Brownian motion with drift, the insurer can purchase excess-of-loss reinsurance and invest his (or her) surplus in a financial market consisting of one risk-free asset and one risky asset whose price is modelled by a CEV model, and the objective of the insurer is to maximize the expected exponential utility from terminal wealth. Two problems are studied, one being a reinsurance-investment problem and the other being an investment-only problem. Explicit expressions for optimal strategies and optimal value functions of the two problems are derived by stochastic control approach and variable change technique. Moreover, several interesting results are found, and some sensitivity analysis and numerical simulations are provided to illustrate our results.

JUNG, E. J.; KIM, J. H. Optimal investment strategies for the HARA utility under the constant elasticity of variance model. 667-673. We give an explicit expression for the optimal investment strategy, under the constant elasticity of variance (CEV) model, which maximizes the expected HARA [hyperbolic absolute risk aversion] utility of the final value of the surplus at the maturity time. To do this, the corresponding HJB equation will be transformed into a linear partial differential equation by applying a Legendre transform. And we prove that the optimal investment strategy corresponding to the HARA utility function converges a.s. to the one corresponding to the exponential utility function.

KUME, A.; HASHORVA, E. Calculation of Bayes premium for conditional elliptical risks. 632-635. In this paper the authors discuss the calculation of the Bayes premium for conditionally elliptical multivariate risks. In our framework the prior distribution is allowed to be very general requiring only that its probability density function satisfies some smoothness conditions. Based on the previous results of Landsman and Nešlehová (2008) [Z. Landsman, J. Nešlehová (2008), Stein's lemma for elliptical random vectors, Journal of Multivariate Analysis, 99, 912-927] and Hamada and Valdez (2008) [M. Hamada, E.A. Valdez (2008), CAPM and option pricing with elliptically contoured distributions, Journal of Risk \& Insurance, 75, 387-409], the authors show 
in this paper that for conditionally multivariate elliptical risks the calculation of the Bayes premium is closely related to the Brown identity and the celebrated Stein's lemma.

LEE, D.; LI, W. K.; WONG, T. S. T. Modelling insurance claims via a mixture exponential model combined with peaks-over-threshold approach. 538-550. We consider a model which allows data-driven threshold selection in extreme value analysis. A mixture exponential distribution is employed as the thin-tailed distribution in view of the special structure of insurance claims, where individuals are often grouped into categories. An EM algorithm-based procedure is described in model fitting. We then demonstrate how a multi-level fitting procedure will substantially reduce computation time when the data set is large. The fitted model is applied to derive statistics such as return level and expected tail loss of the claim distribution, and ruin probability bounds are obtained. Finally we propose a statistical test to justify the choice of mixture exponential distribution over the homogeneous exponential distribution in terms of improved fit.

LIANG, X.; WANG, G. On a reduced form credit risk model with common shock and regime switching. 567-575. Reduced form credit risk models are important ones in credit risk theory. In such a model, certain correlated relations are constructed to represent the default dependence structure among the default intensity processes. In this paper, we introduced a reduced form credit risk model in which the default dependence structures among default intensity processes are described by the so-called common shocks with regime-switching. We derive some closed-form expressions for the joint distribution of the default times and for the pricing formulas of the basket default swaps. We also give numerical results to show the applicable aspects of the proposed model.

LIM, A. E. B.; WATEWAI, T. Optimal investment and consumption when regime transitions cause price shocks. 551-566. This paper concerns optimal investment and consumption with CRRA utility when there is event risk. Events are modelled by transitions in a finite state Markov chain, but unlike traditional regime switching models, transitions not only change the instantaneous return statistics but are accompanied by jumps in the price at the instant of transition. Optimal investment and consumption policies are characterized using stochastic control methods and computed by solving a system of ordinary differential equations and a convex optimization problem. We show that optimal policies are significantly different from those of traditional regime switching or jump-diffusion problems and that the cost of ignoring transition price shocks can be substantial.

LOPEZ, O. A generalization of the Kaplan-Meier estimator for analyzing bivariate mortality under right-censoring and left-truncation with applications in model-checking for survival copula models. 505-516. In this paper we provide a new nonparametric estimator of the joint distribution of two lifetimes under random right censoring and left truncation which can be seen as a bivariate extension of the Kaplan-Meier estimator. We derive asymptotic results for this estimator, including uniform $\mathrm{n}^{1 / 2}$-consistency, and develop a general methodology for bivariate lifetime modelling, a critical issue in studying reversion conditions that are commonplace in defined benefit pensions and private annuity contracts. An application to goodness-of-fit for survival copula models is discussed. We show that the procedures that we use are consistent, and propose a bootstrap procedure based on our estimator to compute the critical values. The new technique that we propose is tested on the Canadian dataset initially studied by Frees et al. (1996). [E W Frees, J F Carriere, E A Valdez (1996), Annuity valuation with dependent mortality, Journal of Risk and Insurance, 63(2) (1996), 229-261]. 
LUO, S.; TAKSAR, M. Minimal cost of a Brownian risk without ruin. 685-693. In this paper, we study an optimal stochastic control problem for an insurance company whose surplus process is modelled by a Brownian motion with drift (the diffusion approximation model). The company can purchase reinsurance to lower its risk and receive cash injections at discrete times to avoid ruin. Proportional reinsurance and excess-of-loss reinsurance are considered. The objective is to find an optimal reinsurance and cash injection strategy that minimizes the total cost to keep the surplus process non-negative (without ruin). Here the cost function is defined as the total discounted value of the injections. The minimal cost function is found explicitly by solving the according quasi-variational inequalities (QVIs). Its associated optimal reinsurance-injection control policy is also found.

MALINOVSKII, V. K. Equitable solvent controls in a multi-period game model of risk. 599-616. In insurance two major types of cycles are known: (a) regular many years long up- and downswings referred to as underwriting cycles and (b) irregular short-range fluctuations. The key rationale of the underwriting cycles is migration of insureds triggered by the insurers' price competition while the short-range fluctuations are due to unpredictable fluctuations in economic surroundings. The competition-originated cycles were modelled in the framework of a Lundberg's-type multi-period model of risk in [Malinovskii, 2010] and [Malinovskii, submitted for publication]. Short-range fluctuations were modelled under diverse nature scenarios in the framework of (i) diffusion (see Malinovskii, 2007 [V.K. Malinovskii (2007), Zone-adaptive control strategy for a multiperiodic model of risk, Annals of Actuarial Science, 2, 391-409] and Malinovskii, 2009 [V.K. Malinovskii (2009), Scenario analysis for a multi-period diffusion model of risk, ASTIN Bulletin, 39, 649-676]) and (ii) Lundberg's-type multi-period model (see Malinovskii, 2008a [V.K. Malinovskii (2008), Adaptive control strategies and dependence of finite time ruin on the premium loading, Insurance: Mathematics and Economics, 42, 81-94]). In this paper the results of Malinovskii (2009) are extended on the Lundberg's-type multi-period model.

OBERLAIN, N. T.; PLANCHET, F. Stochastic evaluation of life insurance contracts: model point on asset trajectories and measurement of the error related to aggregation. 624-631. In this paper, we are interested in the optimization of computing time when using Monte-Carlo simulations for the pricing of the embedded options in life insurance contracts. We propose a very simple method which consists in grouping the trajectories of the initial process of the asset according to a quantile. The measurement of the distance between the initial process and the discretized process is realized by the L2-norm. L2 distance decreases according to the number of trajectories of the discretized process. The discretized process is then used in the valuation of the life insurance contracts. We note that a wise choice of the discretized process enables us to correctly estimate the price of a European option. Finally, the error due to the valuation of a contract in Euro using the discretized process can be reduced to less than $5 \%$.

PENG, X.; CHEN, M.; GUO, J. Optimal dividend and equity issuance problem with proportional and fixed transaction costs. 576-585. This paper investigates the optimal dividend problem of an insurance company, which controls risk exposure by reinsurance and by issuing new equity to protect from bankruptcy. Transaction costs are incurred by these business activities: reinsurance is non-cheap, dividend is taxed and fixed costs are generated by equity issuance. The goal of the company is to maximize the expected cumulative discounted dividend minus the expected discounted costs of equity issuance. This problem is formulated as a mixed regular-singularimpulse stochastic control problem. By solving the corresponding HJB [Hamilton-JacobiBellman] equation, the authors obtain the analytical solutions of the optimal return function and the optimal strategy. 
SADEFO KAMDEM, J.; MOUSSA, A. M.; TERRAZA, M. Fuzzy risk adjusted performance measures: application to hedge funds. 702-712. In this paper, following the notion of probabilistic risk adjusted performance measures, we introduce that of fuzzy risk adjusted performance measures (FRAPM). In order to deal efficiently with the closing-based returns bias induced by market microstructure noise, as well as to handle their uncertain variability, we combine fuzzy set theory and probability theory. The returns are first represented as fuzzy random variables and then used in defining fuzzy versions of some adjusted performance measures. Using a recent ordering method for fuzzy numbers, we propose a ranking of funds based on these fuzzy performance measures. Finally, empirical studies carried out on fifty French hedge funds confirm the effectiveness and give the benefits of our approach over the classical performance ratios.

SADEFO KAMDEM, J.; DEFFO, C. T.; FONO, L. A. Moments and semi-moments for fuzzy portfolio selection. 517-530. The aim of this paper is to consider the moments and the semimoments for credibilistic portfolio selection with fuzzy risk factors (for example trapezoidal risk factors). In order to measure the leptokurtocity of credibilistic portfolio return, notions of moments (for example Kurtosis) and semi-moments (for example Semi-kurtosis) for credibilistic portfolios are originally introduced in this paper, and their mathematical properties are studied. As an extension of the mean-variance-skewness model for credibilistic portfolio, the meanvariance-skewness-semi-kurtosis is presented and its four corresponding variants are also considered. We display numerical examples for our optimization models.

Reproduced with the permission of Elsevier Science.

Subscription details available from: Elsevier Science, PO Box 311, 1000 AE Amsterdam, The Netherlands. E-mail: nlinfo-f@elsevier.nl

Journal of Risk and Insurance

$79(2), 2012$

BAIR, S.-T.; HUANG, R. J.; WANG, K. C. Can vehicle maintenance records predict automobile accidents? 567-584. This article proposes that vehicle maintenance records can provide useful information for predicting the probability that an owner will have an automobile accident. To test the hypothesis, we use a unique data set that is merged from an insurance company and a vehicle manufacturer in Taiwan. We find weak evidence to support our hypothesis. Among all the proxies for proper maintenance, we indicate that proper maintenance defined by the recommended kilometers is significantly negatively correlated with the loss probability in compulsory automobile liability insurance. The average loss probability decreases by 0.23 percent when the insured vehicle is properly maintained according to the recommended number of kilometres in the previous years, whereas the average loss probability for the overall sample is 0.49 percent. We further find that proper maintenance is insignificantly correlated with loss severity.

BERRY-STÖLZLE, T. R; LIEBENBERG, A. P.; RUHLAND, J. S.; SOMMER, D. W. Determinants of corporate diversification: evidence from the property-liability insurance industry. 381-413. This article analyzes variations in line-of-business diversification status and extent among property-liability insurers. Our results show that the extent of diversification is not driven by risk pooling considerations; insurers operating in more volatile business lines do not diversify more. 
Diversification can rather be explained by the benefits of internal capital markets and barriers to business growth like market size and concentration. In our analysis, we distinguish between related and unrelated diversification. Using a measure of unrelated line-of-business diversification we find the first support for the diversification prediction of the managerial discretion hypothesis that mutual insurers should be less diversified than stock insurers. While mutual insurers tend to exhibit higher levels of total diversification, they engage in significantly less unrelated diversification than do stock insurers.

BIKKER, J. A.; STEENBEEK, O. W.; TORRACCHI, F. The impact of scale, complexity, and service quality on the administrative costs of pension funds: A cross-country comparison. 477-514. Administrative costs per participant appear to vary widely across pension funds in different countries. Using unique data on 90 pension funds over the period 2004-2008, this article examines the impact of scale, the complexity of pension plans, and service quality on the administrative costs of pension funds, and compares those costs across Australia, Canada, the Netherlands, and the United States. We find that, except for Canada, large unused economies of scale exist. Higher service quality and more complex pension plans significantly raise costs. Administrative costs vary significantly across pension fund types, with differences amounting to 100 percent.

BROWNE, M. J.; KAMIYA, S. A theory of the demand for underwriting. 335-349. We examine the demand for underwriting and its effect on equilibrium in an insurance market in which insureds know their risk type, but insurers do not. Our analysis indicates that a set of policies including one that requires buyers to take an underwriting test can constitute a full coverage Nash equilibrium when perfect classification is possible. We also find that underwriting equilibria, in which low risks obtain greater coverage than they would without underwriting, widely exist in a Wilsonian market with nonmyopic insurers. Our findings provide a potential explanation for why empirical evidence on adverse selection is mixed.

EECKHOUDT, L.; HUANG, R. J.; TZENG, L. Y. Precautionary effort: a new look. 585-590. While the concept of precautionary saving is well documented, that of precautionary effort has received relatively limited attention. In this note, we set up a two period model in order to analyze the conditions under which the introduction (or deterioration) of an independent background risk increases effort.

ERHEMJAMTS, O.; PHILLIPS, R. D. Form over matter: Differences in the incentives to convert using full versus partial demutualization in the U.S. life insurance industry. 305-334. We explore the recent wave of demutualizations in the U.S. life insurance industry and analyze if the motives were similar for mutual life insurers that fully demutualized versus those that converted to mutual holding company (MHC) form. We find that fully demutualizing insurers were primarily motivated by a desire to gain access to external capital markets while those that chose MHC were motivated by other incentives including a tax-based incentive. We also document that after conversion, fully demutualizing insurers more aggressively increase their exposure to risks they have a comparative advantage to bear than do firms that convert to MHC.

GRACE, M. F.; LEVERTY, J. T. Property-liability insurer reserve error: motive, manipulation, or mistake. 351-380. We use two reserve error definitions found in the literature to investigate the joint impact of previously studied incentives on the magnitude of reserve error. We find many prior conclusions are dependent upon the restricted setting in which the hypotheses are tested and 
on the definition of the reserve error. We find strong evidence that financially weak insurers underreserve to a greater extent than other insurers. However, our evidence casts doubt on the conclusion that insurers manipulate reserves to avoid solvency monitoring. We also find insurers increase reserves for tax purposes and to reduce the impact of regulatory rate suppression.

LAKDAWALLA, D.; ZANJANI, G. Catastrophe bonds, reinsurance, and the optimal collateralization of risk transfer. 449-476. Catastrophe bonds feature full collateralization of the underlying risk transfer and thus abandon the reinsurance principle of economizing on collateral through diversification of risk transfer. Our analysis demonstrates that this feature places limits on catastrophe bond penetration, even if the structure possesses frictional cost advantages over reinsurance. However, we also show that catastrophe bonds have important uses when buyers and reinsurers cannot contract over the division of assets in the event of insolvency and, more generally, cannot write contracts with a full menu of state-contingent payments. In this environment, segregation of collateral-in the form of multiple reinsurance companies, as well as catastrophe bond vehicles-can ameliorate inefficiencies due to reinsurance contracting constraints by improving welfare for those exposed to default risk. Numerical simulation illustrates how catastrophe bonds improve efficiency in market niches with correlated risks, or with uneven exposure of buyers to reinsurer default.

LAZAR, D.; DENUIT, M. M. Multivariate analysis of premium dynamics in P\&L insurance. 431-448. This article studies the dynamic relationship between premiums and losses on the U.S. property-casualty insurance market, accounting for the external impacts of GDP and interest rate. Compared to the existing literature, the present work innovates in that the dynamic relationships between premiums, losses, GDP, and interest rate are studied in a cointegration framework, single-equation and vector approach, involving the long- and short-run dynamics. The results suggest a stable long-run equilibrium between premiums, losses, and general economy. On short term, the premiums adjust quickly and significantly to the long-term disequilibrium and have a strong autoregressive behavior. External factors contribute to explain the dynamics of premiums.

MA, Y-L.; REN, Y. Do publicly traded property-casualty insurers cater to the stock market? 415-430. This article examines the catering theory in the insurance industry. We investigate whether managers of publicly traded insurers pursue a growth strategy catering to the stock market's preference. Two hypotheses are tested in this study: (1) an insurer will devote more efforts to increasing premium growth when the stock market places greater values on growth, and (2) this catering effect will be more pronounced at firms where managers have greater incentives to maximize short-term stock prices. We find evidence supporting both hypotheses. Our study discovers a new channel through which the stock market and executive compensation affect insurance companies' business strategies and the insurance market. The implication of the interplay between insurers and the stock market is significant and deserves future research.

TURVEY, C. G. Whole farm income insurance. 515-540. This article employs a mathematical programming model to investigate farmers' optimal crop choices under gross revenue insurance, whole farm income insurance (WFI), the Canadian Agricultural Income Stabilization (CAIS) program, and its modified 2008 program AgrInvest. WFI poses a particularly interesting problem since the indemnity/premium structure is dependent upon the choice of crops, whereas the choice of crops is simultaneously influenced by the presence of the whole farm insurance program. Results indicate that farmers will alter farm plans significantly in response to the type of insurance offered and the level of subsidy. 
ULM, E. R. Insurance pricing, reserving, and performance evaluation under external constraints on capitalization and return on equity. 541-566. We derive formulas for calculating the premiums that should be charged on policies in a discounted cash flow model with tax reserves and required assets that are determined by regulation. We also determine the unique division of required assets into "reserves" and "capital" that allows the product profitability to be correctly evaluated. That is, the profit after capital charges is zero if the product achieves the return assumed in pricing. We illustrate the concepts using whole life insurance and guaranteed minimum death benefit examples.

Journal of Risk and Insurance

$79(3), 2012$

BIKKER, J. A.; BROEDERS, D. W. G. A.; HOLlANDERS, D. A.; PONDS, E. H. M. Pension funds' asset allocation and participant age: a test of the life-cycle model. 595-618. This article examines the impact of participants' age distribution on the asset allocation of Dutch pension funds, using a unique data set of pension fund investment plans for 2007. Theory predicts a negative effect of age on (strategic) equity exposures. We observe that a 1-year higher average age in active participants leads to a significant and robust reduction of the strategic equity exposure by around 0.5 percentage point. Larger pension funds show a stronger age-equity exposure effect. The average age of active participants influences investment behaviour more strongly than the average age of all participants, which is plausible as retirees no longer possess any human capital.

CHANG, C.-C.; WANG, C.-W.; YANG, C.-Y. The effects of macroeconomic factors on pricing mortgage insurance contracts. 867-895. Numerous empirical studies, including Abraham and Hendershott (1996), Muellbauer and Murphy (1997), Leung (2004), and Oikarinen (2009), have identified a significant relationship between housing prices and macroeconomic factors. Using a linear regression on the co-movement of macroeconomic factors and housing prices, this article employs an option-pricing framework to price and hedge the fair premia of mortgage insurance (MI). Our model provides improved performance in terms of MI premium pricing, especially during periods that are characterized by high housing prices. Ignoring the impacts of macroeconomic factors on housing prices will lead to an underestimation of MI premia.

CHENG, J.; WEISS, M. A. The role of RBC, hurricane exposure, bond portfolio duration, and macroeconomic and industry-wide factors in property-liability insolvency prediction. 723-750. This research analyzes the performance of the risk-based capital (RBC) ratio and other variables in predicting insolvencies in the property-liability insurance industry during the period 1994-2008. The results indicate that the accuracy of the RBC ratio in predicting insolvencies is inconsistent over time and that some previously tested financial ratios that are part of the FAST system do not always reliably predict insurer insolvency. In addition, the insolvency propensity is found to be significantly related to an insurer's hurricane prone area exposure, changes in interest rates, the industry-wide combined ratio, and the industry-wide Herfindahl index of premiums written.

DENG, Y.; BROCKETT, P. L.; MACMINN, R. D. Longevity/mortality risk modelling and securities pricing. 697-721. Securitizing longevity/mortality risk can transfer longevity/mortality risk to capital markets. Modelling and forecasting mortality rate is key to pricing mortality-linked securities. Catastrophic mortality and longevity jumps occur in historical data and have an important impact on security pricing. This article introduces a stochastic diffusion model with a 
double-exponential jump diffusion process that captures both asymmetric rate jumps up and down and also cohort effect in mortality trends. The model exhibits calibration advantages and mathematical tractability while better fitting the data. The model provides a closed-form pricing solution for J.P. Morgan's q-forward contract usable as a building block for hedging.

GATZERT, N.; HOLZMÜLLER, I.; SCHMEISER, H. Creating customer value in participating life insurance. 645-670. The value of a life insurance contract may differ depending on whether it is looked at from the customer's point of view or that of the insurance company. We assume that the insurer is able to replicate the life insurance contract's cash flows via assets traded on the capital market and can hence apply risk-neutral valuation techniques. The policyholder, on the other hand, will take risk preferences and diversification opportunities into account when placing a value on that same contract. Customer value is represented by policyholder willingness to pay and depends on the contract parameters, that is, the guaranteed interest rate and the annual and terminal surplus participation rate. The aim of this article is to analyze and compare these two perspectives. In particular, we identify contract parameter combinations that - while keeping the contract value fixed for the insurer - maximize customer value. In addition, we derive explicit expressions for a selection of specific cases. Our results suggest that a customer segmentation in this sense, that is, based on the different ways customers evaluate life insurance contracts and embedded investment guarantees while ensuring fair values, is worthwhile for insurance companies as doing so can result in substantial increases in policyholder willingness to pay.

GODIN, F.; MAYORAL, S.; MORALES, M. Contingent claim pricing using a normal inverse Gaussian probability distortion operator. 841-866. We consider the problem of pricing contingent claims using distortion operators. This approach was first developed in (Wang, 2000) where the original distortion function was defined in terms of the normal distribution. Here, we introduce a new distortion based on the Normal Inverse Gaussian (NIG) distribution. The NIG is a generalization of the normal distribution that allows for heavier skewed tails. The resulting operator asymmetrically distorts the underlying distribution. Moreover, we show how we can recuperate non-Gaussian Black-Scholes formulas using distortion operators and we provide illustrations of their performance. We conclude with a brief discussion on risk management applications.

INKMANN, J.; MICHAELIDES, A. Can the life insurance market provide evidence for a bequest motive? 671-695. Using U.K. microeconomic data, we analyze the empirical determinants of participation in the life insurance market. We find that term insurance demand is positively correlated with measures of bequest motives like being married, having children, and/or subjective measures of strong bequest motives. We then show that a life-cycle model of life insurance demand, saving, and portfolio choice can rationalize quantitatively the data in the presence of a bequest motive. These findings provide evidence supporting the presence of a bequest motive.

LEVERTY, J. T.; GRACE, M. F. Dupes or incompetents? An examination of management's impact on firm distress. 751-783. This article examines whether managers impact firm performance. We conservatively define managerial ability as the manager's capacity to deploy the firm's resources. We verify the validity of our metric using a manager-firm matched panel data set that allows us to track managers (CEOs) across different firms over time. We find managerial ability is inversely related to the amount of time a firm spends in distress, the likelihood of a firm's failure, and the cost of failure. These results suggest that the managers of failed firms are less skilled than their counterparts. But even within failed firms there is heterogeneity in the talents of managers. 
LIEBENBERG, A. P.; CARSON, J. M.; DUMM, R. E. A dynamic analysis of the demand for life insurance. 619-644. Prior research suggests that neither the choice to own life insurance nor the amount purchased is consistently related to the presence of children in the household. While these perplexing findings are based on a static framework, we alternatively examine life insurance demand in a dynamic framework as a function of changes in household life cycle and financial condition. Our results indicate both a statistically and economically significant relation between life events, such as new parenthood, and the demand for life insurance. We also provide new evidence in support of the emergency fund hypothesis: households in which either spouse has become unemployed are more likely than other households to surrender their whole life insurance.

NORTH, C. M.; GARVEN, J. R; GWIN, C. R. Rainfall or rainmaking? Lawyers, courts, and the price of mold insurance in Texas. 817-839. In well-functioning property-liability insurance markets, the price of coverage reflects the impact of the legal environment on the frequency and severity of claims. This article presents a case study of the Texas mold insurance crisis of 2001-2002. We provide a narrative of the controversy in Texas over insurance coverage for household mold and use county-level data from a single Texas insurer to assess the determinants of postcrisis prices for supplemental mold, slab, and extended water loss coverages. We find that more attorneys per capita and more heavily Democratic courts were both associated with higher prices for mold and slab coverage.

RYMASZEWSKI, P.; SCHMEISER, H.; WAGNER, J. Under what conditions is an insurance guaranty fund beneficial for policybolders? 785-815. In this article, we derive conditions in an imperfect market setting, under which the introduction of a self-supporting insurance guaranty fund improves the position of the policyholders. When a guaranty fund is advantageous given homogeneous firms in the market, all policyholders benefit from it to the same extent, if they have the same underlying risk preferences and are charged identical premiums. In a more realistic heterogeneous setting, the introduction of an insurance guaranty fund is in general no longer beneficial for all policyholders in the same manner. Hence, systematic wealth transfers take place between the policyholders of different insurance companies. As a possible solution, and in order to counteract this effect, we introduce a framework for utility-based fund charges.

Reproduced with the permission of the American Risk and Insurance Association.

Subscription details available from: the American Institute for CPCU, 720 Providence Road, Malvern, PA 19355, USA. E-mail: aria@cpcuiia.org

North American Actuarial Journal

$16(2), 2012$

AUGUSTYNIAK, M.; BOUDREAULT, M. An out-of-sample analysis of investment guarantees for equity-linked products: Lessons from the financial crisis of the late 2000s. 183-206. In this paper we analyze the risk underlying investment guarantees using 78 different econometric models: GARCH, regime-switching, mixtures, and combinations of these approaches. This extensive set of models is compared with returns observed during the financial crisis in an out-of-sample analysis, bringing a new perspective to the study of equity-linked insurance. We find that despite the very good fit of recent models, too few of them are capable of consistently generating low returns over long periods, which were in fact observed empirically during the financial crisis. 
Moreover, tail risk measures vary significantly across models, and this emphasizes the importance of model risk. Most insurance companies are now focusing on dynamically hedging their investment guarantees, and so we also investigate the robustness of the Black-Scholes delta hedging strategy. We find that hedging errors can be very large among the top fitting models, implying that model risk must be taken into consideration when hedging investment guarantees.

FUJISAWA, Y.; LI, J. S.-H. The impact of the automatic balancing mechanism for the public pension in japan on the extreme elderly. 207-239. Most developed countries are seeking ways to maintain a sustainable social security system. Japan is no exception. The old-age dependency ratio in Japan is currently $35 \%$ and is expected to be $74 \%$ in 2050 . Recently the Japanese government has adopted an automatic balancing mechanism, which gradually reduces the real price of the public pension through a reduction of inflation adjustments. The reduction, depending on future demographics, is a random process, so the elderly, in particular the extreme elderly, have to take the risk of receiving an inadequate public pension. The objectives of this paper are threefold. First, we review the recent trends in Japanese mortality and explain the underlying longevity issues that led to the automatic balancing mechanism. Second, by means of stochastic mortality and fertility modelling, we analyze how demographic changes will affect the future of public pensions in Japan. Third, we demonstrate, on the basis of the stochastic projections we made, how the automatic balancing mechanism will affect the financial security for people who live beyond age 100 .

LAI, T. L.; SUN, K. H. Evolutionary credibility theory: A generalized linear mixed modelling approach. 273-284. The conventional approach to evolutionary credibility theory assumes a linear state-space model for the longitudinal claims data so that Kalman filters can be used to estimate the claims' expected values, which are assumed to form an autoregressive time series. We propose a class of linear mixed models as an alternative to linear state-space models for evolutionary credibility and show that the predictive performance is comparable to that of the Kalman filter when the claims are generated by a linear state-space model. More importantly, this approach can be readily extended to generalized linear mixed models for the longitudinal claims data. We illustrate its applications by addressing the "excess zeros" issue that a substantial fraction of policies does not have claims at various times in the period under consideration.

MARSHALL, C.; HARDY, M.; SAUNDERS, D. Measuring the effectiveness of static hedging strategies for a guaranteed minimum income benefit. 143-182. A guaranteed minimum income benefit (GMIB) is a long-dated option that can be embedded in a deferred variable annuity. The GMIB is attractive because, for policyholders who plan to annuitize, it offers protection against poor market performance during the accumulation phase. This paper analyzes the effectiveness of static hedging strategies for the GMIB. Using Monte Carlo simulation, the effectiveness of a static hedging strategy is measured by the empirical hedging loss distribution, where each hedging loss is defined as the difference between the GMIB payoff and the hedging portfolio payoff at the maturity date. Hedging portfolios are constructed by minimizing the Conditional Tail Expectation of the hedging loss distribution or minimizing the mean-squared hedging loss. The positions in the hedging portfolio instruments are determined at the outset from solving either portfolio optimization problem and are held fixed until the maturity date. Our results suggest which instruments are most important to achieve the best results. We backtest the performance of static hedging strategies for the GMIB over the period 1961 to 2012.

SCOLLNIK, D. P. M.; SUN, C. Modelling with Weibull-Pareto models. 260-272. In this paper we develop several composite Weibull-Pareto models and suggest their use to model loss payments 
and other forms of actuarial data. These models all comprise a Weibull distribution up to a threshold point, and some form of Pareto distribution thereafter. They are similar in spirit to some composite lognormal-Pareto models that have previously been considered in the literature. All of these models are applied, and their performance compared, in the context of a real world fire insurance data set.

VERRALL, R. J.; WÜTHRICH, M. V. Reversible jump Markov chain Monte Carlo method for parameter reduction in claims reserving. 240-259. We present an application of the reversible jump Markov chain Monte Carlo (RJMCMC) method to the important problem of setting claims reserves in general insurance business for the outstanding loss liabilities. A measure of the uncertainty in these claims reserves estimates is also needed for solvency purposes. The RJMCMC method described in this paper represents an improvement over the manual processes often employed in practice. In particular, our RJMCMC method describes parameter reduction and tail factor estimation in the claims reserving process, and, moreover, it provides the full predictive distribution of the outstanding loss liabilities.

\section{North American Actuarial Journal}

$16(3), 2012$

COLE, C. R.; EASTMAN, K. L.; MARONEY, P. F.; MCCULLOUGH, K. A.; MACPHERSON, D. The impact of no-fault legislation on automobile insurance. 306-322. Since its inception, the effectiveness of no-fault legislation has been highly debated. Although some research suggests that no-fault laws are effective in reducing costs, other evidence suggests that the current no-fault systems may not meet the original objectives. This study provides a detailed assessment of the relation of no-fault laws and automobile insurance losses for the period 1994 to 2007 . By examining total automobile insurance losses along with liability and personal injury protection losses, we are able to determine if and how specific provisions of the laws are related to claims costs. We find a negative relation between the presence of a no-fault law and total losses, which suggests that no-fault systems are associated with lower losses than the traditional tort system. In addition, an examination of no-fault-only states suggests that specific provisions of no-fault laws, such as thresholds and limitations on benefits, have some effect on losses. With the sunset of Colorado's no-fault legislation in 2003, the recent passage of Personal Injury Protection Reform in Florida, and proposed federal choice legislation, the overall impact of no-fault as well as the specific components of the laws are of heightened importance to consumers, insurers, and lawmakers.

DEBÓN, A.; MARTÍNEZ-RUIZ, F.; MONTES, F. Temporal evolution of mortality indicators: application to Spanish data. 364-377. In Spain, as in other developed countries, significant changes in mortality patterns have occurred during the 20th and 21 st centuries. One reflection of these changes is life expectancy, which has improved in this period, although the robustness of this indicator prevents these changes from being of the same order as those for the probability of death. If, moreover, we bear in mind that life expectancy offers no information as to whether this improvement is the same for different age groups, it is important and necessary to turn to other mortality indicators whose past and future evolution in Spain we are going to study. These indicators are applied to Spanish mortality data for the period 1981-2008, for the age range 0-99. To study its future evolution, the mortality ratios have to be projected using an adequate methodology, namely, the Lee-Carter model. Confidence intervals for these predictions can be 
calculated using the methodology that Lee and Carter apply in their original article for expected lifetime confidence intervals, but they take into account only the error in the prediction of the mortality index obtained from the ARIMA model adjusted to its temporal series, excluding other sources of error such as that introduced by estimations of the other parameters in the model. That is why bootstrap procedures are preferred, permitting the combination of all sources of uncertainty.

EMMS, P. Equilibrium pricing of general insurance policies. 323-349. A model is developed for determining the price of general insurance policies in a competitive, non-cooperative market. This model extends previous single-optimizer pricing models by supposing that each participant chooses an optimal pricing strategy. Specifically, prices are determined by finding a Nash equilibrium of an N-player differential game. In the game, a demand law describes the relationship between policy sales and premium, and each insurer aims to maximize its (expected) utility of wealth at the end of the planning horizon. Two features of the model are investigated in detail: the effect of limited total demand for policies, and the uncertainty in the calculation of the breakeven (or cost price) of an insurance policy. It is found that if the demand for policies is unlimited, then the equilibrium pricing strategy is identical for all insurers, and it can be found analytically for particular model parameterizations. However, if the demand for policies is limited, then, for entrants to a new line of business, there are additional asymmetric Nash equilibria with insurers alternating between maximal and minimal selling. Consequently it is proposed that the actuarial cycle is a result of price competition, limited demand, and entry of new insurers into the market. If the breakeven premium is highly volatile, then the symmetric equilibrium premium loading tends to a constant, and it is suggested that this will dampen the oscillatory pricing of new entrants.

KELLY, M.; KLEFFNER, A.; LI, S. Loss reserves and the employment status of the appointed actuary. 285-305. Property/casualty (P/C) insurers are required to establish loss reserves for unpaid losses at the time that the loss has occurred or is reasonably expected to have occurred. We examine factors that may impact the accurate setting of loss reserves. These include the level of rate regulation faced by the insurer and the incentives to underestimate or overestimate reserves to improve financial ratios or improve solvency scores, to reduce earnings, to defer taxes, or to smooth earnings volatility in order to meet shareholder expectations. The employment status of the Appointed Actuary, that is, whether the Appointed Actuary is an employee of the firm or a consultant, may also impact reserve accuracy. Using a variety of regression models with data from 1995 to 2010, we examine the impact of these factors on the accuracy of reserves posted by Canadian P/C insurers. Our results provide no evidence of systematic differences in the magnitude or direction of loss reserve errors between insurers that use company actuaries versus those that use consultant actuaries. However, we find that for both consultant and company actuaries positive reserve errors are associated with increases in global stock market returns and decreases in unanticipated inflation. The insurance market cycle impacts reserve errors for company actuaries and not consultant actuaries. As well, our results indicate that as the proportion of short-tailed business increases in a company, consultant actuaries are more likely to over-reserve. Similar to many previous studies using U.S. data, we do not find strong evidence regarding insurers' incentives to deliberately overstate or understate reserves: Loss reserves are relatively unbiased estimates of the true losses paid. Thus these findings should be welcome news to the actuarial profession in Canada and to the prudential regulator: The Appointed Actuary, regardless of employment status, provides objective and unbiased estimates of insurers' largest liability.

TANG, Q.; YUAN, Z. A bybrid estimate for the finite-time ruin probability in a bivariate autoregressive risk model with application to portfolio optimization. 378-397. Consider a 
discrete-time risk model in which the insurer is allowed to invest a proportion of its wealth in a risky stock and keep the rest in a risk-free bond. Assume that the claim amounts within individual periods follow an autoregressive process with heavy-tailed innovations and that the logreturns of the stock follow another autoregressive process, independent of the former one. We derive an asymptotic formula for the finite-time ruin probability and propose a hybrid method, combining simulation with asymptotics, to compute this ruin probability more efficiently. As an application, we consider a portfolio optimization problem in which we determine the proportion invested in the risky stock that maximizes the expected terminal wealth subject to a constraint on the ruin probability.

WÜTHRICH, M. V. Discussion of Paper Already Published: A Bayesian Log-Normal Model for Multivariate Loss Reserving. 398-401. Discussion of the previously published paper "A Bayesian Log-Normal Model for Multivariate Loss Reserving” by Peng Shi, Sanjib Basu and Glenn G. Meyers.

ZHU, L.; LI, H. Asymptotic analysis of multivariate tail conditional expectations. 350-363. Tail conditional expectations refer to the expected values of random variables conditioning on some tail events and are closely related to various coherent risk measures. In the univariate case, the tail conditional expectation is asymptotically proportional to Value-at-Risk, a popular risk measure. The focus of this paper is on asymptotic relations between the multivariate tail conditional expectation and Value-at-Risk for heavy-tailed scale mixtures of multivariate distributions. Explicit tail estimates of multivariate tail conditional expectations are obtained using the method of regular variation. Examples involving multivariate Pareto and elliptical distributions, as well as application to risk allocation, are also discussed.

Reproduced with the permission of the Society of Actuaries.

Subscription details available from: Society of Actuaries, 475 N. Martingale Road, Schaumburg, ILL 60173 USA, www.soa.org

Scandinavian Actuarial Journal

2,2012

ERHARDT, V.; CZADO, C. Modelling dependent yearly claim totals including zero claims in private health insurance. 106-129. In insurance applications yearly claim totals of different coverage fields are often dependent. In many cases there are numerous claim totals which are zero. A marginal claim distribution will have an additional point mass at zero, hence this probability function (pf) will not be continuous at zero and the cumulative distribution functions will not be uniform. Therefore using a copula approach to model dependency is not straightforward. We will illustrate how to express the joint pf by copulas with discrete and continuous margins. A pair-copula construction will be used for the fit of the continuous copula allowing to choose appropriate copulas for each pair of margins.

KOROLEV, V.; SHEVTSOVA, I. An improvement of the Berry-Esseen inequality with applications to Poisson and mixed Poisson random sums. 81-105. By a modification of the method that was applied in study of Korolev \& Shevtsova (2009), here the inequalities $\rho\left(F_{n}, \Phi\right) \leqslant 0.33477\left(\beta^{3}+\right.$ $0.429) / \sqrt{n}$ and $\rho\left(F_{n}, \Phi\right) \leqslant 0.3041\left(\beta^{3}+1\right) / \sqrt{n}$ are proved for the uniform distance $\rho\left(F_{n}, \Phi\right)$ between the standard normal distribution function $\mathrm{F}$ and the distribution function $F_{n}$ of the normalized 
sum of an arbitrary number $n \geqslant 1$ of independent identically distributed random variables with zero mean, unit variance, and finite third absolute moment $\beta^{3}$. The first of these two inequalities is a structural improvement of the classical Berry-Esseen inequality and as well sharpens the best known upper estimate of the absolute constant in the classical Berry-Esseen inequality since $0.33477\left(\beta^{3}+0.429\right) \leqslant 0.33477(1+0.429) \beta^{3}<0.4784 \beta^{3}$ by virtue of the condition $\beta^{3}=1$. The latter inequality is applied to lowering the upper estimate of the absolute constant in the analog of the Berry-Esseen inequality for Poisson random sums to 0.3041 which is strictly less than the least possible value $0.4097 \ldots$ of the absolute constant in the classical Berry-Esseen inequality. As corollaries, the estimates of the rate of convergence in limit theorems for compound mixed Poisson distributions are refined.

WOO, J.-K. A generalized penalty function for a class of discrete renewal processes. 130-152. Analysis of a generalized Gerber-Shiu function is considered in a discrete-time (ordinary) Sparre Andersen renewal risk process with time-dependent claim sizes. The results are then applied to obtain ruin-related quantities under some renewal risk processes assuming specific interclaim distributions such as a discrete $\mathrm{K} \mathrm{n}$ distribution and a truncated geometric distribution (i.e. compound binomial process). Furthermore, the discrete delayed renewal risk process is considered and results related to the ordinary process are derived as well.

\section{Scandinavian Actuarial Journal}

3,2012

BARRIEU, P.; BENSUSAN, H.; EL KAROUI, N.; HILLAIRET, C.; LOISEL, S.; RAVANELLI, C.; SALHI, Y. Understanding, modelling and managing longevity risk: key issues and main challenges. 203-231. This article investigates the latest developments in longevity-risk modelling, and explores the key risk management challenges for both the financial and insurance industries. The article discusses key definitions that are crucial for the enhancement of the way longevity risk is understood, providing a global view of the practical issues for longevity-linked insurance and pension products that have evolved concurrently with the steady increase in life expectancy since s. In addition, the article frames the recent and forthcoming developments that are expected to action industry-wide changes as more effective regulation, designed to better assess and efficiently manage inherited risks, is adopted. Simultaneously, the evolution of longevity is intensifying the need for capital markets to be used to manage and transfer the risk through what are known as Insurance-Linked Securities (ILS). Thus, the article will examine the emerging scenarios, and will finally highlight some important potential developments for longevity-risk management from a financial perspective with reference to the most relevant modelling and pricing practices in the banking industry.

CHEUNG, E. C. K. A unifying approach to the analysis of business with random gains. 153-182. In this paper, we consider a stochastic model in which a business enterprise is subject to constant rate of expenses over time and gains which are random in both time and amount. Inspired by Albrecher \& Boxma (2004), it is assumed in general that the size of a given gain has an impact on the time until the next gain. Under such a model, we are interested in various quantities related to the survival of the business after default, which include: (i) the fair price of a perpetual insurance which pays the expenses whenever the available capital reaches zero; (ii) the probability of recovery by the first gain after default if money is borrowed at the time of default; and 
(iii) the Laplace transforms of the time of recovery and the first duration of negative capital. To this end, a function resembling the so-called Gerber-Shiu function (Gerber \& Shiu (1998)) commonly used in insurance analysis is proposed. The function's general structure is studied via the use of defective renewal equations, and its applications to the evaluation of the abovementioned quantities are illustrated. Exact solutions are derived in the independent case by assuming that either the inter-arrival times or the gains have an arbitrary distribution. A dependent example is also considered and numerical illustrations follow.

DICKSON, D. C. M.; LI, S. Erlang risk models and finite time ruin problems. 183-202. We consider the joint density of the time of ruin and deficit at ruin in the $\operatorname{Erlang}(n)$ risk model. We give a general formula for this joint density and illustrate how the components of this formula can be found in the special case when $n=2$. We then show how the formula can be implemented numerically for a general value of $\mathrm{n}$. We also discuss how the ideas extend to the generalised $\operatorname{Erlang}(n)$ risk model.

Reproduced with the permission of Taylor \& Francis, http://www.tandf.co.uk/journals/SACT

South African Actuarial Journal

12,2012

BUTLER, M. B. J.; VAN ZYL, C. J. Consumption changes on retirement for South African bouseholds. 1-29. This paper presents the results of an investigation into whether age or work status are statistically significant determinants of the change in the consumption rate at and in retirement. This research used data from the Income and Expenditure Survey 2005-2006 for households comprising one or two adults. It was found that gifting and non-healthcare consumption, which includes gifting, are not influenced by age or work status. Certain households were found to have higher healthcare consumption after retirement than before retirement. This result challenges the belief that retired households have lower consumption than working households, all other things equal, and may therefore necessitate an upward adjustment to retirement adequacy goals.

BUTLER, M. B. J.; VAN ZYL, C. J. Retirement adeqaucy goals for South African households. 31-64. Despite the importance of retirement adequacy goals to public policy, retirement fund design and personal financial planning, there has been little formal research on the estimation of retirement adequacy goals for South African households. This research derived estimated retirement adequacy goals for employed one- and two-adult households. A consumptionsmoothing model with a minimum-income underpin was developed to estimate wealth-earnings ratio goals using data from the Income and Expenditure Survey 2005-2006. Household wealthearnings ratio goals were estimated to be between 10,5 and 18,2 times annual salary depending on retirement age, household composition, income, location, age, education, household income distribution, home ownership and salary support. Considering current retirement savings rates, retirement before age 67 is unlikely to be affordable for most households.

DAVIS, R. W. D.; KENDAL, S. Surplus? What surplus? Did the pension funds second amendment achieve its aims? 97-128. The Pension Funds Second Amendment Act, 2001 required funds to provide statutory minimum benefits for exiting members and pensioners. Any surplus arising at the statutory valuation following the promulgation of this Act was to be distributed-initially to 
former members and pensioners to top up their benefits to the statutory minimum, and then equitably to all stakeholders. Surplus available in retirement funds was originally estimated at R80bn, but the surplus distributed by May 2012 was only about R47,6bn. This paper considers some reasons for this discrepancy and, in particular, gives an analysis of 447 surplus valuation reports. It shows that, by strengthening their valuation assumptions and motivating contingency reserves, actuaries reduced the surplus by R10bn for these 447 funds. The paper questions whether the strengthening of valuation bases was justified and examines critically the new actuarial methods introduced following the promulgation of the Act.

GANZ, M. D. The effect of SAM [Solvency Assessment and Management] on the South African medical-scheme environment: a quantitative analysis. 65-96. The globalisation of the financial services industry and the increasing complexity of insurance products, among other factors, have led to the development of new regulatory systems for insurers globally (and, in particular, in South Africa). The primary intention of these systems is to protect the interests of policyholders by ensuring that insurance companies remain solvent in most foreseeable circumstances. In South Africa, new regulation, known as Solvency Assessment and Management (SAM), is expected in 2015 , but this regulation is to apply only to insurance companies and not to medical schemes. This paper considers the implications of the application of capital requirements under Quantitative Impact Study 1 to the measurement of capital adequacy in South African medical schemes. Data from 2006, 2007 and 2008 were used to parameterise the non-SLT health-underwriting risk module (i.e. the risk module relating to health-underwriting risk that is not similar to life techniques), which was then used to determine the level of economic capital that schemes would have been required to hold in 2009. The results showed an overall reduction in the capital requirements of medical schemes, as compared with the current statutory minimum requirements, and therefore an increase in the proportion of medical schemes that are found to be solvent.

PLAKS, S.; BUTLER, M. B. J. Access to public healthcare in South Africa. 129-164. Access to healthcare is considered to be a basic human right. This paper explores the concept of access to public healthcare, with a particular focus on affordability, accessibility and accommodation. Furthermore, it highlights certain issues around the concept of access in the South African setting, by analysing the results from the General Household Surveys (2002-2009). Affordability of healthcare services and the positioning of the facilities were not identified as being key barriers to access. Instead, other aspects, such as accommodation to the patients' needs and acceptability of services received had greater significance and should be prioritised in terms of any proposed healthcare reforms.

Reproduced with the permission of the Actuarial Society of South Africa.

Access to issues via: http://www.actuarialsociety.org.za/South-African-Actuarial-Journal-671.aspx

Variance

$5(2), 2011$

BOUCHER, J.-P.; DAVIDOV, D. On the importance of dispersion modeling for claims reserving: an application with the Tweedie distribution. 158-172. We consider Tweedie's compound Poisson model in a claims reserving triangle in a generalized linear model framework. We show that there exist practical situations where the variance, as well as the mean of the costs, needs to be 
modeled. We optimize the likelihood function through either direct optimization or through double generalized linear models (DGLM). We also enhance the estimation of the variance parameters within the DGLM by using the restricted maximum likelihood (REML). Having a flexible variance structure allows the model to replicate the underlying risk more appropriately and shrinks the gap between the predicted variances of different models.

D'ARCY, S. P. Capital allocation in the property-liability insurance industry. 141-157. Capital allocation is a theoretical exercise, since all of a firm's capital could be depleted to cover a significant loss arising from any one segment. However, firms do need to allocate capital for pricing, risk management, and performance evaluation. One versatile allocation method, the Ruhm-MangoKreps algorithm, has several key advantages: additivity, simplicity, and flexibility. However, the approach is so flexible that it can be used to produce many different values instead of a single answer. In this paper, the cost of capital in financial markets is incorporated into the Ruhm-Mango-Kreps algorithm to yield one allocation that reflects the true cost of capital an insurer would face.

MAJOR, J. A. Risk valuation of property-casualty insurers. 124-140. Risk valuation is the process of assigning a monetary value to a transformation of risk. Risk transformation can come about through changes in the operation of a business, explicit risk transfer mechanisms, financial changes, etc. This paper reviews the application of valuation techniques to address the question: "Does this risk transformation create or destroy shareholder value?" Four broad classes of valuation models are compared: actuarial appraisal/valuation, economic capital, firm life annuity, and optimal dividends. Their key differences are seen to lie in their treatment of the firm's mortality and the circumstances under which recapitalization can occur.

TAYLOR, G. Chain ladder correlations. 115-123. Correlations of future observations are investigated within the recursive and non-recursive chain-ladder models. The recursive models considered are the Mack and over-dispersed Poisson (ODP) Mack models; the non-recursive models are the ODP cross-classified models. Distinct similarities are found between the correlations within the recursive and non-recursive models, but distinct differences also emerge. The ordering of corresponding correlations within the recursive and non-recursive models is also investigated.

WANG, S. S.; MAJOR, J. A.; HUCHENG, P. (C.); LEONG, W. K. U.S. property-casualty: underwriting cycle modeling and risk benchmarks. 91-114. The risk benchmarks and underwriting cycle models presented here can be used by insurers in their enterprise risk management models. We analyze the historical underwriting cycle and develop a regimeswitching model for simulating future cycles, and show its superiority to an autoregressive approach. We compute benchmarks for pricing and reserving risks by line of business and by industry segments (large national, super regional, and small regional). We also compute the historical correlation of the loss ratio, as well as the correlation of changes in the reserve estimate between lines of business.

Reproduced with the permission of the Casualty Actuarial Society.

Access to Variance issues via: http://www.variancejournal.org/issues/

Subscription details available from: Casualty Actuarial Society, 4350 N. Fairfax Drive, Suite 250, Arlington, VA 22203. USA. Tel.: +1 (703) 276-3100; Fax: +1 (703) (703) 276-3108, office@casact.org. 